Universidade de São Paulo

Faculdade de Economia, Administração e Contabilidade de Ribeirão Preto Departamento DE EConomia

Programa de Pós-Graduação em Economia - Área: Economia Aplicada

VITOR DIAS ROCIO

\title{
Um modelo espaço-temporal contínuo para o preço de lançamentos imobiliários na cidade de São Paulo
}

Orientador: Prof. Dr. Márcio Poletti Laurini

Ribeirão Preto 
Prof. Dr. Vahan Agopyan

Reitor da Universidade de São Paulo

\section{Prof. Dr. Dante Pinheiro Martinelli}

Diretor da Faculdade de Economia, Administração e Contabilidade de Ribeirão Preto

Prof. Dr. Renato Leite Marcondes

Chefe do Departamento de Economia

Prof. Dr. Sergio Naruhiko Sakurai

Coordenador do Programa de Pós-Graduação em Economia 


\section{Um modelo espaço-temporal contínuo para o preço de lançamentos imobiliários na cidade de São Paulo}

Dissertação de mestrado apresentada ao Programa de Pós-Graduação em Economia Área: Economia Aplicada da Faculdade de Economia, Administração e Contabilidade de Ribeirão Preto da Universidade de São Paulo para obtenção do título de Mestre em Ciências. Versão Corrigida. A original encontra-se disponível na FEA-RP/USP.

Orientador: Prof. Dr. Márcio Poletti Laurini

Ribeirão Preto 
Autorizo a reprodução e divulgação total ou parcial deste trabalho, por qualquer meio convencional ou eletrônico, para fins de estudo e pesquisa, desde que citada a fonte.

ROCIO, Vitor Dias.

Um modelo espaço-temporal contínuo para o preço de lançamentos imobiliários na cidade de São Paulo / Vitor Dias Rocio Ribeirão Preto, SP, 2018.

57 p.: il.; $30 \mathrm{~cm}$

Dissertação de mestrado apresentada ao Programa de PósGraduação em Economia - Área: Economia Aplicada da Faculdade de Economia, Administração e Contabilidade de Ribeirão Preto da Universidade de São Paulo, para obtenção do título de Mestre em Ciências. - Universidade de São Paulo

Orientador: Laurini, Márcio Poletti

1. Econometria Espacial. 2. Co-Integração Espacial. 3. Métodos Bayesianos. 
Para meus pais Pedro e Maria, minha irmã Manuela e minha noiva Natasha. 


\section{Agradecimentos}

Aos meus pais e à minha irmã por todo o apoio que foi fundamental para a conclusão desta etapa da minha vida.

À minha noiva Natasha por estar ao meu lado nos melhores e piores momentos de minha vida.

Ao meu orientador Márcio Laurini pelos ensinamentos, orientações e contribuições ao longo do mestrado e que sempre esteve disposto a ajudar.

A todos os professores do PPGE/FEARP/USP com os quais tive contato em sala de aula.

A todos os técnicos e funcionários da FEARP/USP pela atenção, apoio e profissionalismo.

A todos os colegas do PPGE/FEARP/USP que de alguma forma direta ou indiretamente ajudaram nesta jornada.

À CAPES pelo apoio financeiro concedido ao longo do mestrado. 


\section{Resumo}

ROCIO, V. D. Um modelo espaço-temporal contínuo para o preço de lançamentos imobiliários na cidade de São Paulo. Dissertação (Mestrado) - Faculdade de Economia, Administração e Contabilidade de Ribeirão Preto, Universidade de São Paulo, Ribeirão Preto, 2018.

Neste trabalho será feito um modelo espaço-temporal contínuo para preços de imóveis na cidade de São Paulo estimado através de métodos Bayesianos. Faremos uma decomposição da série em tendência e ciclo além de incorporar um conjunto de variáveis explicativas e efeitos aleatórios espaciais projetados no contínuo. Este modelo introduz um novo método para analisar a formação dos preços dos lançamentos imobiliários. Consideramos em nosso modelo hedônico, além das características intrínsecas, também as características da vizinhança e o ambiente econômico. Com este modelo, conseguimos observar os preços de equilíbrio para as respectivas localizações e uma interpretação mais clara da dinâmica de preços dos imóveis entre janeiro de 2000 e dezembro de 2013 para a cidade de São Paulo.

Palavras-chaves: Econometria Espacial, Co-Integração Espacial, Equações Diferenciais Parciais Estocásticas, Métodos Bayesianos, Estatística Espacial. 


\begin{abstract}
ROCIO, V. D. A continuous space-time model for the price of real estate launches in the city of São Paulo. Dissertation (Master Degree) - School of Economics, Business and Accounting at Ribeirão Preto, University of São Paulo, Ribeirão Preto, 2018.

In this work will be made a continuous spatial-temporal model for real estate prices in the city of São Paulo estimated using Bayesian methods. We will decompose the series into a trend and cycle, and incorporate a set of explanatory variables and random spatial effects projected into the continuum. This model introduces a new method to analyze the price formation of real estate launches. We consider in our hedonic model, besides the intrinsic characteristics, also the characteristics of the neighborhood and the economic environment. With this model, we were able to observe the equilibrium prices for the respective locations and a clearer interpretation of the dynamics of real estate prices between January 2000 and December 2013 for the city of São Paulo.
\end{abstract}

Keywords: Spatial Econometrics, Spatial Co-Integration, Stochastic Partial Differential Equations, Bayesian Methods, Spatial Statistics. 


\section{Lista de ilustrações}

Figura 5.1 - Mapa de Lançamentos Imobiliários. . . . . . . . . . . . . . . . . . . . . 28

Figura 5.2 - Iluminação Noturna - Cidade de São Paulo. . . . . . . . . . . . . . . . 29

Figura 5.3 - Mapa de Escolas. . . . . . . . . . . . . . . . . . . . . . . . . 31

Figura 5.4 - Mapa de Unidade Básica de Saúde. . . . . . . . . . . . . . . . . . . . 31

Figura 5.5 - Mapa de Favelas e loteamentos. . . . . . . . . . . . . . . . . . . . . . 32

Figura 5.6 - Gráfico do Preço por metro quadrado . . . . . . . . . . . . . . . . . . 32

Figura 6.1 - Triangulação de Mesh e lançamentos imobiliários . . . . . . . . . . . . 36

Figura 6.2 - Gráfico de tendência e ciclo - modelo completo . . . . . . . . . . . . . . 40

Figura 6.3 - Gráfico de tendência e ciclo - modelo restrito pelo DIC . . . . . . . . . 41

Figura 6.4 - Efeito Aleatório - SPDE-Matérn - modelo Completo . . . . . . . . . . . 42

Figura 6.5 - Efeito Aleatório - SPDE-Matérn - modelo Restrito . . . . . . . . . . . 42

Figura 6.6 - modelo Ajustado - modelo restrito selecionado pelo critério DIC . . . . 43

Figura 6.7 - Gráfico de Tendência e Ciclo - ICAR . . . . . . . . . . . . . . . . 45

Figura 6.8 - Efeito Aleatório - ICAR . . . . . . . . . . . . . . . . . . 46

Figura 6.9 - Gráfico de Tendência - modelo com efeito dinâmico anual . . . . . . . . 47

Figura 6.10-Efeito Aleatório - modelo dinâmico 2000-2003 . . . . . . . . . . . . . . 48

Figura 6.11-Efeito Aleatório - modelo dinâmico 2004-2007 . . . . . . . . . . . . . . 48

Figura 6.12-Efeito Aleatório - modelo dinâmico 2008-2011 _ . . . . . . . . . . . . . 49

Figura 6.13-Efeito Aleatório - modelo dinâmico 2012-2013 . . . . . . . . . . . . . . 49

Figura 6.14-Efeito Aleatório - modelo dinâmico Variação 2000-2013 . . . . . . . . . 50

Figura 6.15-Triangulação Alternativa de Mesh . . . . . . . . . . . . . . . . 50

Figura 8.1 - Mapa geográfico com a cidade de São Paulo. . . . . . . . . . . . . . . . 57 


\section{Lista de tabelas}

Tabela 5.1 - Estatísticas Descritivas . . . . . . . . . . . . . . . . . 30

Tabela 6.1 - Resultados - Estimação do modelo sem efeitos aleatórios . . . . . . . . 35

Tabela 6.2 - Resultados - Estimação do modelo Completo . . . . . . . . . . . . . . 37

Tabela 6.3 - Resultados - Estimação do modelo Final - Critério significância . . . 38

Tabela 6.4 - Resultados - Estimação do modelo Final DIC . . . . . . . . . . . . . . 39

Tabela 6.5 - Resultados - Estimação do modelo ICAR . . . . . . . . . . . . . . . . . 44

Tabela 6.6 - Modelo com estrutura dinâmica para os efeitos aleatórios espaciais efeitos anuais .......................... 47

Tabela 6.7 - modelo com estrutura dinâmica para os efeitos aleatórios espaciais efeitos mensais . . . . . . . . . . . . . . . . 51

Tabela 6.8 - Resultados de Ajuste . . . . . . . . . . . . . . . . . . . 52 


\section{Sumário}

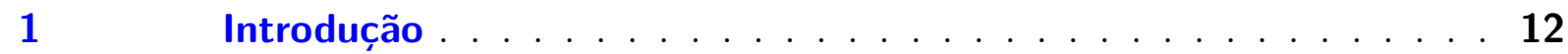

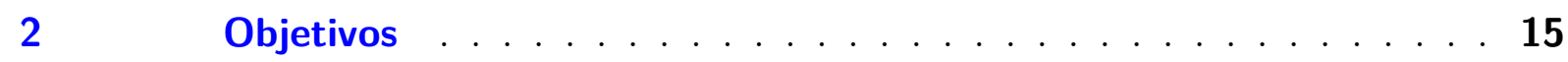

3 Revisão bibliográfica . . . . . . . . . . . . . . . . . . 15

$4 \quad$ Metodologia . . . . . . . . . . . . . . . 17

4.1 Modelo espaço-temporal SPDE-Matérn . . . . . . . . . . . . 18

$4.2 \quad$ ICAR: Um caso especial do SPDE . . . . . . . . . . . . 23

$4.3 \quad$ Inferência Bayesiana . . . . . . . . . . . . . . . . . 23

4.3.1 Modelo Bayesiano hierárquico . . . . . . . . . . . . . . . 23

4.3.2 Modelos dinâmicos usando INLA . . . . . . . . . . . . . . . . 25

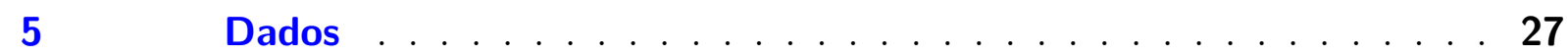

$6 \quad$ Resultados . . . . . . . . . . . . . . . . . 33

$6.1 \quad$ Modelos sem componentes latentes . . . . . . . . . . . . . . . . 34

6.2 Modelos com efeitos aleatórios espaciais fixos no tempo . . . . . . . 34

$6.3 \quad$ Comparação com o modelo ICAR . . . . . . . . . . . . . . . 43

6.4 Modelo com estrutura dinâmica para os efeitos aleatórios espaciais . . . . . 43

6.5 Resultados de ajuste . . . . . . . . . . . . . . 51

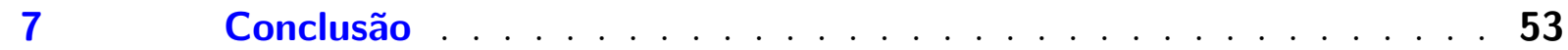

Referências ..................... . . 54

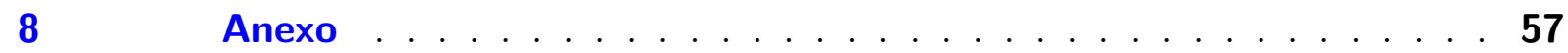




\section{Introdução}

A habitação é, provavelmente, o bem de consumo de longo prazo mais importante em economias modernas. Ela provê essencialmente segurança em forma de abrigo e um espaço que pode ser utilizado para diversos usos sendo, um dos mais significativos, o de ser base para se criar uma família. Ao adquirir um imóvel, o consumidor obtém além dos direitos de usufruir das características intrínsecas, como o seu tamanho, números de quartos, banheiros, vagas de garagem entre outros, o de também lograr de um amplo conjunto de externalidades positivas ou negativas de acordo com a localização da sua propriedade. O imóvel ocupado pelo dono também é considerado um investimento. Na maioria dos casos, através de externalidades positivas, proporciona ganhos de capital para os proprietários a longo prazo. Em contrapartida, para os casos de externalidades negativas, como favelização nos arredores, desastres naturais ou até mesmo guerras, podem ocorrer perdas parciais ou integrais do capital investido nesse bem.

Schiller (2000) afirma que movimentos de valorização e queda no preço dos imóveis estão relacionados de forma direta aos períodos de expansão e recessão econômica. Estes movimentos nos preços dos imóveis afetam diretamente o investimento do proprietário o que gera impactos no estoque de riqueza das famílias e empresas.

No âmbito do mercado financeiro, temos alguns ativos que são atrelados de forma direta ou indireta ao setor imobiliário e, em sua maioria, representam títulos de crédito imobiliário, tais como, o CRI (Certificados de Recebíveis Imobiliários), a LCI (Letras de Crédito Imobiliário), a CCI (Cédulas de Crédito Imobiliário) e a LH (Letras Hipotecárias). Ao citar os títulos de hipotecas, recordamos da crise financeira global de 2008.

Essa crise de 2008, desencadeada nos Estados Unidos, conhecida como "crise do subprime", teve suas origens em uma bolha de preços de ativos que interagiu com novos tipos de inovações financeiras que mascararam o risco existente nesses ativos, em conjunto com uma possível bolha formada nos mercados imobiliários, com o preço das casas aumentando desde 1990 até 2006. As expectativas de aumentos de preços futuros se desenvolveram e foram um fator significativo no inflacionamento dos preços das casas. O colapso veio com a rápida desvalorização do preço dos imóveis após uma rápida e vultuosa valorização nos anos precedentes, tendo um pico de valor no ano de 2006, como explicitado em Baily, Litan e Johnson (2008). Esta crise gerou efeitos que não só afetaram o sistema financeiro americano como também se espalhou por todo o mundo. Expondo que há evidências para uma relação direta entre o setor imobiliário e o meio financeiro, pode-se dizer que também há uma relação entre o setor imobiliário e a economia como um todo.

Outro fato importante ao se analisar o comportamento dos preços imobiliários é no que diz respeito à decomposição nas componentes de tendência e ciclo. Intervalos de tempo em que há valorização excessiva de preços ou bolhas podem ser identificados através 
dos desvios sistemáticos dos determinantes econômicos desses preços. Em Holly, Pesaran e Yamagata (2010) é possível encontrar uma análise da relação entre preços de imóveis e seus fundamentos econômicos através de um modelo de correção de erros (co-integração). Holly, Pesaran e Yamagata (2010) encontraram uma relação de cointegração (determinar se as séries envolvidas possuem ou não uma relação de longo prazo) entre o preço do imóvel com a renda e a taxa de juros.

O artigo de Alves et al. (2011) encontrou evidências de que, em períodos de alta valorização no mercado de capitais - no caso em análise a BOVESPA-, existem importantes mudanças na formação dos preços dos imóveis residenciais na cidade de São Paulo.

No nosso estudo, apresentamos uma metodologia inovadora de análise de preços de imóveis usando uma decomposição de tendência e ciclos em um modelo espaço-temporal com efeitos aleatórios projetados continuamente no espaço, generalizando a metodologia proposta em Laurini (2016a). Aplicamos essa decomposição da estrutura da média (tendência e ciclo) para os preços individuais de novos lançamentos de imóveis residenciais na cidade de São Paulo para os anos de 2000 até 2013.

A fonte de dados utilizada nesse estudo apresenta alguns problemas particularmente difíceis para a análise de séries temporais. O primeiro deles refere-se à dimensionalidade da base: o processo de interesse é a evolução contínua do preço de lançamento relacionada aos lançamentos em localidades distintas. Os métodos econométricos para a extração das componentes de tendência e ciclo são geralmente baseados em modelos univariados ou de baixa dimensão, devido à complexidade computacional para a maximização da função de máxima verossimilhança. A segunda dificuldade é que nos diferentes períodos temos lançamentos em áreas distintas, em outras palavras, teríamos uma observação para cada lançamento.

Para solucionar estas duas dificuldades citadas anteriormente, iremos realizar uma projeção dos lançamentos em cada instante de tempo no contínuo espacial, e modelar a evolução desta projeção através de componentes de tendência e ciclos estocásticos e efeitos aleatórios espaciais. A projeção contínua no espaço permite resolver o problema de observações irregulares no tempo e espaço, em um procedimento similar a uma interpolação espacial (krigging), usando uma matriz de covariância espacial contínua da classe Matérn.

Para modelar o preço do metro quadrado dos lançamentos, utilizaremos um modelo em que iremos decompor o preço em quatro fatores principais: o efeito de covariadas $z(s, t) \beta$, tendência $\left(\mu_{t}\right)$, ciclo $\left(c_{t}\right)$ e efeitos aleatórios espaciais, $\xi_{t}$, na forma:

$$
\begin{gathered}
y(s, t)=\mu_{t}+c_{t}+z(s, t) \beta+\xi(s, t)+\epsilon(s, t) \\
\mu_{t}=\mu_{t-1}+\eta_{\mu} \\
c_{t}=\phi_{1} c_{t-1}+\phi_{2} c_{t-2}+\eta_{c} \\
\xi_{t}=\rho \xi_{t-1}+\omega_{t}
\end{gathered}
$$


onde $y(s, t)$ representa a observação $y$ na localização $s$ e no período $t ; \mu_{t}$ e $c_{t}$ são os componentes de tendência e ciclo, com componentes de inovação Gaussianos independentes $\eta_{\mu}$ e $\eta_{c}$, e $z(s, t)$ um conjunto de covariadas observadas na localização $s$ e no período $t$, $\epsilon(s, t), \eta_{\mu}$ e $\eta_{c}$ são componentes Gaussianos independentes de inovação e $\xi(s, t)$ é efeito aleatório espacial, representado por um processo $\omega(s, t)$ projetado continuamente no espaço e caracterizado pela função de covariância espacial $\mathcal{C}(h)$, sendo $\mathcal{C}(h)$ uma função de covariância Matérn contínua.

A tendência $\left(\mu_{t}\right)$ é o comportamento de longo prazo da série mostrando a evolução geral dos preços, e o ciclo $\left(c_{t}\right)$ captura padrões periódicos de valorização e queda nos preços. O ponto central deste trabalho é mostrar que somente os componentes hedônicos não são suficientes para explicar a dinâmica de preços de imóveis já que não capturam movimentos de tendências sistemáticas ou ciclos de valorizações e quedas observados em mercados imobiliários, e também não capturam de forma adequada a heterogeneidade espacial dos preços de imóveis.

Para realizar a estimação do modelo da equação (1.1) adaptamos o procedimento de inferência introduzido em Lindgren, Rue e Lindström (2011). Por meio da equivalência entre a solução de uma determinada equação diferencial parcial estocástica (do inglês, Stochastic Partial Differential Equation - SPDE) e uma função de covariância espacial, os autores mostram que é possível representar um processo de covariância espacial no contínuo. Além de poder representar alguns processos espaciais contínuos através dos métodos de elementos finitos, esta formulação também pode ser relacionada a campos aleatórios gaussianos de Markov, em que poderá ser utilizado o método de estimação bayesiano representado pelas aproximações aninhadas de Laplace (do inglês, Integrated Nested Laplace Approximations - INLA), propostas por Rue, Martino e Chopin (2009). Tanto a abordagem SPDE quanto o INLA serão melhor explicados na seção Metodologia.

Muitos métodos de decomposições estruturais de séries temporais (por exemplo, Harvey (1990)) com componentes de tendência e ciclo, não estão totalmente adaptadas aos dados de modelagem espacial. Nossa contribuição é combinar a representação espacial contínua, citada anteriormente, com estas decomposições estruturais de séries de tempo. Umas das principais motivações deste método é a de que estamos modelando os preços individuais, sem a necessidade de usar agregações por bairros, áreas, etc. Neste trabalho usamos a informação de cada lançamento de forma pontual, sem recorrer a agregações que podem induzir distorções importantes no processo de inferência. Além disso, controlamos a estrutura de dependência espacial, o que dará um realismo maior ainda ao trabalho ao permitir estimar a contribuição espacial não explicada pelas variáveis hedônicas e os componentes de tendência e ciclo.

Nosso trabalho está dividido em sete Seções, organizados da seguinte maneira: A Seção 1 é a introdução, onde apresentamos os primeiros conceitos e a motivação para a 
modelagem de preços no município de São Paulo. Em seguida temos a Seção 2, em que dizemos qual será o nosso objetivo geral e específico para o trabalho. A Seção 3 refere-se a revisão bibliográfica, em que apresentamos um pouco da literatura correlacionada com a modelagem de preços. Na Seção 4 apresentamos a metodologia básica do trabalho, onde é apresentado um pouco mais dos métodos utilizados: SPDE-Matérn e os modelos dinâmicos no INLA. As próximas seções são, respectivamente: Dados (Seção 5) e Resultados (Seção 6). Para a seção Dados, especificamos o uso da base de dados do CEM (Centro de Estudos da Metrópole) e das variáveis selecionadas e, na seguinte, apresentamos os resultados encontrados. A Seção 7 apresenta as conclusões finais do trabalho.

\section{Objetivos}

O objetivo geral deste trabalho será modelar o preço dos lançamentos imobiliários na cidade de São Paulo. A principal contribuição desse trabalho é introduzir uma nova metodologia que permite incorporar componentes sistêmicos (tendência, ciclos e efeitos espaciais) aos modelos hedônicos de preços, e também modelar preços individuais de ativos sem o uso de agregações, aumentando o grau de realismo e precisão do modelo.

Esta metodologia também é uma forma de contornar os problemas associados às modelagens de econometria espacial, como os modelos CAR (Conditional Autoregressive Models) e SAR (Spatial Autoregressive Models), que usam apenas a informação relacionada aos vizinhos mais próximos na análise dos efeitos espaciais e usualmente não incorporam efeitos dinâmicos. Usaremos uma especificação análoga a de modelos geoestatísticos, onde assumimos que a mensuração ocorre em localizações específicas. Também analisaremos um caso especial do modelo padrão CAR em que converge para um caso especial de SPDE com uma restrição na definição do campo aleatório.

\section{Revisão bibliográfica}

A literatura sobre a modelagem de preço dos imóveis é bem vasta. Nesta seção, iniciaremos com uma apresentação de alguns trabalhos acerca da formação de preço dos imóveis a partir de características intrínsecas, como número de dormitórios, garagem, entre outros atributos, ademais pela formação de preços a partir de características hedônicas, como características da vizinhança, do bairro, entre outros. Por fim, citamos um trabalho que usa análise espacial em conjunto com a modelagem hedônica.

O modelo de preço hedônico é utilizado de forma ampla pela literatura quando o assunto é modelar o preço dos imóveis. Neste tipo de abordagem, a composição do preço do imóvel é decomposta em diversos atributos que o compõe. Alves et al. (2011) definem 
preço hedônico como o preço implícito das características de um bem revelado a partir de um grupo de características específicas associados a ele. Este método procura estimar os preços das características de forma individual através de uma decomposição do preço do bem complexo.

Existem muitos trabalhos acerca da estimação do preço do imóvel a partir de características além da propriedade. Freeman (1981) usa a influência de amenidades ambientais, no caso, a qualidade do ar para mensurar o impacto no preço da habitação. Outro trabalho que segue nessa linha, mas que avalia o impacto da poluição sonora emitida pelo apito dos trens nos valores habitacionais, é o do Clark (2006). Tita, Petras e Greenbaum (2006) mostram a relação do crime com o mercado imobiliário local.

Já em Holly, Pesaran e Yamagata (2010), os autores modelam a dinâmica do ajustamento dos preços reais do mercado imobiliário em 49 estados dos Estados Unidos da América, ao longo de quase trinta anos, via aplicações em econometria espacial encontrando significância para os níveis de dependência espacial entre os preços reais dos imóveis e a renda real. De forma relacionada ao presente trabalho, Laurini (2016a) mostra como adaptar a representação de Holly, Pesaran e Yamagata (2010) para um processo contínuo espacial.

Há também alguns estudos voltados para o Brasil. Teixeira e Serra (2016) estimam os custos da criminalidade em Curitiba através do método hedônico. Faria et al. (2009) analisaram a valorização dos imóveis residenciais através da influência de um projeto de saneamento básico no local.

Mais próximo ao nosso trabalho, Alves et al. (2011), estimaram uma regressão dos preços da habitação hedônicos, com base em dados sobre as vendas de imóveis na cidade de São Paulo, durante o período de janeiro de 2001 a março de 2008. Cabe ressaltar que a variável dependente utilizada neste trabalho foi o preço por metro quadrado útil do imóvel. Uma característica interessante diz respeito às variáveis de distância. Entre as conclusões encontradas no trabalho, algumas merecem destaque: a distância do imóvel aos parques apresentou efeito negativo e significante no preço por metro quadrado dos novos empreendimentos, o que significa que, quanto mais próximo for o imóvel de um parque, mais valorizado ele será. O efeito inverso foi encontrado pelos autores para a proximidade do imóvel com a favela. Eles encontraram um efeito positivo na variável distância para a favela em que, quanto mais longe a favela está do imóvel, mais valorizado ele será. Na conclusão dos autores, o distanciamento do imóvel em $10 \%$ de uma favela, valoriza o preço do metro quadrado em aproximadamente $0,5 \%$. O mesmo pode-se dizer da proximidade do imóvel ao metrô, quanto mais perto é o imóvel do metrô mais próximo, mais valorizado ele será.

Alguns outros trabalhos mais recentes da literatura têm usado as características espaciais em conjunto com a modelagem do preço hedônico. Por exemplo, Bowen (2001) 
mostra a necessidade de incluir diagnósticos espaciais como parte do procedimento padrão de ajuste de modelos hedônicos para o preço de imóveis uma vez que ele encontrou "diferenças drásticas"entre o modelo hedônico sem o diagnóstico espacial e o modelo com o diagnóstico.

Do acima exposto, tanto a modelagem a partir de características intrínsecas do imóvel quanto a modelagem de preços hedônicos, evoluíram bastante no sentido de serem feitas com diferentes tipos de variáveis. Contudo, pouco destaque foi dado aos efeitos não explicados pelo modelo hedônico, como componentes de tendência, ciclo e espacial, sendo a nossa principal inovação a forma como introduzimos o efeito espacial. Portanto, este nosso trabalho visa avançar neste sentido na modelagem de preços dos imóveis.

\section{Metodologia}

Nesta seção, iremos apresentar alguns métodos essenciais para o realizar a estimativa do modelo geral dado pela equação (1.1). A principal característica desse processo é que ele pode ser representado como um campo aleatório Gaussiano Markoviano, o que permite algoritmos eficientes de representação e inferência. Nessa seção, descrevemos os procedimentos associados a este processo.

De forma sucinta, para determinar um campo aleatório Gaussiano é necessário especificar a sua matriz de covariâncias. Contudo, como as matrizes de covariâncias são integralmente densas, leva que as inferências exibem complexidades computacionais quando se usam as matrizes de covariância de forma direta. Para transpor este problema recorre-se à metodologia INLA (Integrated Nested Laplace Approximations) desenvolvida por Rue, Martino e Chopin (2009). Todavia, para que possamos usar a metodologia INLA, é necessário que o campo Gaussiano (domínio contínuo) seja um campo Gaussiano de Markov, deste modo, recorre-se a metodologia SPDE (Stochastic Partial Differential Equations), introduzida por Lindgren, Rue e Lindström (2011), que permite obter essa aproximação.

Para a primeira subseção, usaremos como base o trabalho de Lindgren, Rue e Lindström (2011) que apresenta procedimentos de representação eficientes de processos espacias contínuos usando a representação SPDE, para a subseção seguinte, apresentaremos de forma sucinta o caso em que um modelo CAR padrão converge para um caso especial de SPDE, por último, apresentaremos as aproximações integradas aninhadas de Laplace propostas por Rue, Martino e Chopin (2009). 


\subsection{Modelo espaço-temporal SPDE-Matérn}

O uso da metodologia SPDE, proposta por Lindgren, Rue e Lindström (2011), é feita, principalmente, para aproximar o campo Gaussiano - domínio contínuo - de um campo Gaussiano Markoviano - de domínio discreto. De forma geral, mostra-se que um campo Gaussiano com função de covariância Matérn também pode ser verificado como uma solução de equação diferencial parcial estocástica que permite recorrer ao método dos elementos finitos para construir a aproximação. Este método dos elementos finitos recorre aos métodos numéricos para aproximar a solução de equações diferenciais através da discretização da região de elementos menores.

Usamos este método pois uma das suas principais vantagens é a de que podemos fazer qualquer tipo de discretização do espaço geográfico sem a necessidade de ser algo baseado em fronteiras artificiais, como é feito na maior parte dos trabalhos relacionados à modelagem de econometria espacial. Por exemplo, usa-se a divisão do espaço a partir de uma grelha regular à região em estudo. No entanto, para o caso em que temos fronteiras muito irregulares, geralmente dará origem a células nulas.

Já na representação de Lindgren, Rue e Lindström (2011), será possível fazer uma representação contínua dos efeitos espaciais para o modelo espaço-temporal que será apresentado neste trabalho. Nos basearemos nesta metodologia pois teremos, assim, representações computacionalmente eficientes de modelos espaciais e espaço-temporais.

Este conceito é baseado na correspondência entre a solução de uma classe de equações diferenciais parciais e funções de covariância espaciais. A representação da função de covariância espacial é feita como um campo aleatório Gaussiano Markoviano. A metodologia implementada em Lindgren, Rue e Lindström (2011), por explorar uma versão contínua dos efeitos espaciais da propriedade Markoviana espacial, é computacionalmente e numericamente eficiente.

Pode-se dizer que é computacionalmente eficiente porque explora uma versão contínua dos efeitos espaciais da propriedade Markoviana espacial e, além disso, através desta metodologia podemos utilizar métodos de inferência Bayesiana baseados nas aproximações de Laplace, o que permite uma estimação em tempos computacionalmente reduzidos e com maior precisão. Diz-se que é numericamente eficiente pois são utilizadas matrizes esparsas (possui uma grande quantidade de elementos nulos) e também apresenta uma representação contínua dos efeitos aleatórios espaciais com elementos finitos. Sendo assim, permite a caracterização de processos espaciais e espaço-temporais como Campos Aleatórios Gaussianos Markovianos (Gaussian Markov Random Fields - GMRF).

A estrutura que será apresentada abaixo dos Campos Aleatórios Gaussianos foram apresentados por Arbia (2006) e Rue e Held (2005). Foram utilizados grafos não direcionados para representar esta estrutura: $\mathcal{G}=\{\mathcal{V}, \mathcal{E}\}$, sendo $\mathcal{V}$ os nodos e $\mathcal{E}$ o conjunto $\{i, j\}$ de 
vértices, $\operatorname{com} i, j \in \mathcal{V}$.

Seguindo o trabalho de Rue e Held (2005), o vetor aleatório $x=\left(x_{1}, x_{2}, \ldots, x_{k}\right)^{T} \in$ $\mathbb{R}^{n}$ representa um Campo Aleatório Gaussiano Markoviano com respeito ao grafo $\mathcal{G}=\{\mathcal{V}, \mathcal{E}\}$, com médias $E(x)=\mu$ e precisão $Q$ se e somente se a sua densidade pode ser escrita como $\pi(x)=(2 \pi)^{-n / 2}|Q|^{1 / 2} \exp \left(-\frac{1}{2}(x-\mu)^{T} Q(x-u)\right), \operatorname{com} Q_{i j} \neq 0 \leftrightarrow\{i, j\} \in \mathcal{G} \vee i \neq j$.

Lindgren, Rue e Lindström (2011) baseiam-se no resultado de dois trabalhos, Rozanov (1977) e Whittle (1954). Nesse resultado é demonstrado que um campo Gaussiano, $\left\{Z(u), u \in D \subset \mathbb{R}^{d}\right\}$, com função de covariância Matérn é a única solução estacionária da seguinte equação diferencial parcial estocástica (SPDE):

$$
(k-\Delta)^{\alpha / 2} x(u)=W(u)
$$

com $u \in \mathbb{R}^{d}, \alpha=v+\frac{d}{2}, k>0$ e $v>0$ são os parâmetros da função de covariância Matérn. Temos que $(k-\Delta)^{\alpha / 2}$ é um operador pseudo-diferencial, e $W(u)$ um componente de ruído branco espacial Gaussiano com variância unitária e $\Delta$ um operador de Laplace representando:

$$
\Delta=\sum_{i=1}^{d} \frac{\partial^{2}}{\partial x_{i}^{2}}
$$

A variância marginal do processo pode ser escrita da seguinte forma:

$$
\sigma^{2}=\frac{\Gamma(v)}{\Gamma(v+d / 2)(4 \pi)^{d / 2} k^{2 v} \tau^{2}}
$$

$\tau$ é um parâmetro que pode depender do espaço como, por exemplo, no caso de não-estacionariedade, permitindo manter a variância do ruído branco Gaussiano constante. Esta relação é utilizada em Lindgren, Rue e Lindström (2011) para obter valores numéricos da estrutura contínua da covariância espacial, em que se emprega o método apresentado em Brenner e Scott (2007), usando o fato de que a solução da SPDE pode ser representada por elementos finitos. Usando a expansão para esta representação, chegamos em uma certa triangulação em que podemos representar o processo contínuo através de uma expansão:

$$
x(u)=\sum_{i=1}^{n} \psi_{k}(u) \omega_{k}
$$

sendo $\psi_{k}(u)$ a escolha de funções da base e $\omega_{k}$ os pesos estocásticos, que são distribuídos de forma Gaussiana e $n$ é o número de vértices da triangulação. Os pesos representam o valor do campo aleatório de cada vértice e a distribuição dos pesos é dada pela equação diferencial parcial citada anteriormente (Equação 4.1) para um dado conjunto de funções 
teste $\phi_{k}$, e no interior dos triângulos, cada valor é obtido através de uma interpolação como mostrado em Lindgren, Rue e Lindström (2011).

São feitas duas escolhas usuais destas funções que determinam as propriedades de aproximação do campo aleatório discretizado: $\alpha=1$ e $\alpha=2$. Para o caso de $\alpha=1$ chegamos em $\phi_{k}=(k-\Delta)^{1} / 2 \psi_{k}$, e para o caso de $\alpha=2$ encontramos $\phi_{k}=\psi_{k}$, sendo estas duas representações soluções de mínimos quadrados e Galerkin, respectivamente, de acordo com Brenner e Scott (2007).

Uma escolha usual é $\alpha=2$, pois impõe uma estrutura de suavidade e será usada em nossa análise, pois estamos nos baseando em Lindgren, Rue e Lindström (2011). Uma especificação alternativa leva a um resultado de convergência relacionado a um modelo CAR (Conditional Autoregressive), que permite uma comparação com os modelos discretos utilizados nas modelagens tradicionais. Na Seção 4.2 discutimos essa especificação.

Partindo de um campo aleatório continuamente indexado $Y(s, l)$, para que possamos obter uma representação hierárquica de um modelo espaço-temporal, como feito em Cameletti et al. (2013), chegamos na seguinte expressão baseadas no trabalho anteriormente citado:

$$
Y(s, l)=\left\{y(s, l):(s, l) \in D \subseteq \mathbb{R}^{2} \times \mathbb{R}\right\}
$$

em que $s$ denota uma localização espacial e $l$ denota um índice de tempo. Para o nosso trabalho, este modelo é importante pois é caracterizado por uma covariância espaçotemporal, ou seja, $\operatorname{Cov}\left((s, t)\left(s^{\prime}, t^{\prime}\right)\right)=\sigma^{2} C\left((s, l)\left(s^{\prime}, l^{\prime}\right)\right)$, em que, $(s, l)$ e $\left(s^{\prime}, l^{\prime}\right) \subseteq \mathbb{R}^{2} \times \mathbb{R}$. Assume-se que esta covariância é estacionária e depende apenas dos intervalos espaciais e temporais, sendo $h=\left(s-s^{\prime}\right)$ o intervalo espacial e $l=\left(t-t^{\prime}\right)$ o intervalo temporal. Com isso, formulamos o processo através de uma representação hierárquica espaço-temporal:

$$
\operatorname{Cov}\left(\omega\left(s_{i}, t\right)\left(s_{j}, t^{\prime}\right)\right)=\left\{\begin{array}{ccc}
0 & \text { se } & t \neq t^{\prime} \\
\sigma_{\omega}^{2} C(h) & \text { se } & \mathrm{t}=\mathrm{t}^{\prime}
\end{array}\right\}
$$

com a representação hierárquica encontrada nas equações acima, temos que $z(s, t)$ representa as variáveis explicativas observadas no espaço $s$ e tempo $t, \xi(s, t)$ denota os efeitos aleatórios espaciais para cada par $(s, t)$, e os elementos de $\varepsilon(s, t)$ são componentes de inovações não sistemáticos e não espaciais. Tendo $\varepsilon(s, t)$ uma distribuição normal com média zero e variância $\sigma_{\varepsilon}^{2}$.

O desenvolvimento temporal dos efeitos aleatórios através do espaço é representado pelo segundo nível da formulação hierárquica, tendo uma dinâmica temporal dada por $\xi(s, t)=\rho \xi(s, t-1)+\omega(s, t)$ para $t=2, \ldots, T$ e com a condição inicial dada por $\xi(s, 1) \backsim$ 
$N\left(0, \sigma_{\varepsilon}^{2} /\left(1-a^{2}\right)\right)$. Com isso, o processo $\omega(s, t)$ será um campo aleatório:

$$
\operatorname{Cov}\left(\omega\left(s_{i}, t\right)\left(s_{j}, t^{\prime}\right)\right)=\left\{\begin{array}{ccc}
0 & \text { se } & t \neq t^{\prime} \\
\sigma_{\omega}^{2} C(h) & \text { se } & \mathrm{t}=\mathrm{t}
\end{array}\right\}
$$

sendo $C(h)$ uma função covariância da classe Matérn:

$$
C(h)=\frac{1}{\Gamma(v) 2^{v-1}}(k h)^{v} K_{v}(k h)
$$

onde $K_{v}$ é uma função de Bessel modificada de segundo tipo e de ordem $v>0, k>0$ é o parâmetro de escala, $\Gamma$ é a função Gama usual exposta por Abramowitz e Stegun (1964). A interpretação mais usual do parâmetro de escala, $k$, é recorrendo ao conceito de alcance (range). O alcance $r_{0}$ é a distância Euclidiana a partir da qual $Z\left(u_{i}\right)$ e $Z\left(u_{j}\right)$ são quase independentes. Sendo $Z\left(u_{i}\right)$ é uma variável aleatória Gaussiana univariada. Em geral, considera-se a seguinte relação entre os parâmetros

$$
r_{0}=\frac{\sqrt{8 v}}{k}
$$

Empilhando as observações para cada índice espacial, podemos reescrever este modelo na forma:

$$
\begin{aligned}
& y_{t}=z_{t} \beta+\xi_{t}+\varepsilon_{t} \\
& \xi_{t}=a \xi_{t-1}+\omega_{t}
\end{aligned}
$$

Desta forma, as nossas variáveis observadas e de estado (latente) são definidas como $y_{t}=\left(y\left(s_{1}, t\right), \ldots y\left(s_{d}, t\right)\right)^{\prime}, z_{t}=\left(z\left(s_{1}, t\right), \ldots, z\left(s_{d}, t\right)\right)^{\prime}, \xi_{t}=\left(\xi\left(s_{1}, t\right), \ldots, \xi\left(s_{d}, t\right)\right)^{\prime}$, com $\varepsilon_{t}(s, t) \backsim N\left(0, \sigma_{\varepsilon}^{2} I_{d}\right)$ e $\omega_{t} \backsim N\left(0, \Sigma=\sigma_{\omega}^{2} \bar{\Sigma}\right)$.

Sendo $\bar{\Sigma}$ uma matriz de correlação d-dimensional com elementos $C\left(\left\|s_{i}-s_{j}\right\|\right)$, sendo $C$ a matriz Matérn (Equação 4.8). Seja $\theta=\beta, \alpha, \sigma_{\varepsilon}^{2}, k, \tau$ o nosso vetor de parâmetros. Através do lema de Bayes, temos que a posteriori é definida como:

$$
\pi(\theta, \xi \mid y) \propto \pi(y \mid \xi, \theta) \pi(\theta)
$$

Para obter a distribuição posterior do processo, usaremos a propriedade em que os elementos de $y_{i}$ são condicionalmente independentes. Como temos uma estrutura de distribuições priores independentes para $\pi(\theta)$ e usando a propriedade Markoviana, obtemos a distribuição posteriori do processo:

$$
\pi(\theta, \xi \mid y) \propto\left(\prod_{t=1}^{T} \pi(y \mid \xi, \theta)\right)\left(\pi\left(\xi_{1} \mid \theta\right) \prod_{t=2}^{T} \pi\left(\xi_{t} \mid \xi_{t-1}, \theta\right)\right) \pi(\theta)
$$


Assumindo-se distribuição Gaussiana, podemos escrever este processo como:

$$
\begin{array}{r}
\pi(\theta, \xi \mid y)=\left(\sigma_{\varepsilon}^{2}\right)^{d T / 2} \exp \left(-\frac{1}{\sigma_{\varepsilon}^{2}} \sum_{t=1}^{T}\left(y_{t}-z_{t} \beta-\xi\right)^{\prime}\left(y_{t}-z_{t} \beta-\xi_{t}\right)\right) \\
\times\left(\frac{\sigma_{\varepsilon}^{2}}{1-a^{2}}\right)^{-d / 2}|\Sigma|^{-(\bar{T}-1) / 2)} \exp \left(\frac{1-a^{2}}{2 \sigma_{\varepsilon}^{2}} \xi_{1}^{\prime} \bar{\Sigma} \xi_{1}\right) \\
\times\left(\sigma_{\varepsilon}^{2}\right)^{-d(T-1) / 2}|\bar{\Sigma}|^{-(T-1) / 2} \exp \left(\frac{1}{2 \sigma_{\varepsilon}^{2}}\left(\xi_{t}-a \xi_{t-1}\right)^{\prime} \bar{\Sigma}\left(\xi_{t}-a \xi_{t-1}\right)\right) \\
\times \prod_{i=1}^{\operatorname{dim}(\theta)} \pi\left(\theta_{i}\right)
\end{array}
$$

Agora precisamos relacionar este processo com a triangulação e com a representação de elementos finitos do processo contínuo espacial. De acordo com Lindgren, Rue e Lindström (2011), temos que $\omega_{t}$, campo de Matérn, é um aleatório Gaussiano Markoviano com distribuição $N\left(0, Q_{s}^{-1}\right)$, sendo a matriz $Q_{s}$ oriunda da solução de uma equação diferencial parcial estocástica. Tomando $Q_{s}$ invariante no tempo e sendo a sua dimensão dada pelo número de vértices da triangulação. Reparametrizando a equação de estado com a dinâmica de efeitos aleatórios chegamos em:

$$
\begin{aligned}
\xi_{t} & =\rho \xi_{t-1}+\omega_{t} \\
\omega_{t} & \backsim N\left(0, Q_{s}^{-1}\right)
\end{aligned}
$$

com $\mathrm{t}=1, \ldots, \mathrm{T}$ e $\xi_{1} \backsim N\left(0, Q_{s}^{-1} /\left(1-\rho^{2}\right)\right)$. Assim é possível obter a distribuição conjunta de $\xi=\left(\xi_{1}, \ldots, \xi_{T}\right)$ como $\xi \backsim N\left(0, Q^{-1}\right)$, e $Q=Q_{T} \otimes Q_{s}$, com $\otimes$ sendo um produto de Kronecker (ver Cameletti et al. (2013)).

$$
\left(\begin{array}{cccc}
\sigma_{\omega}^{2} & -\rho / \sigma_{\omega}^{2} & & \\
-\rho / \sigma_{\omega}^{2} & \left(1+\rho^{2}\right) / \sigma_{\omega}^{2} & & \\
& & & \\
& \cdots & \\
& & \\
& & \\
& \left(1+\rho^{2} / \sigma_{\omega}^{2}\right) & -\rho / \sigma_{\omega}^{2} \\
& -\rho / \sigma_{\omega}^{2} & \sigma_{\omega}^{2}
\end{array}\right)
$$

Essa representação é computacionalmente mais eficiente e conveniente pois esta representação de matrizes esparsas reduz sensivelmente a necessidade de armazenamento e o número de operações necessárias na análise destes processos espaço-temporais. 
Como observado por Bolin (2012), esta metodologia baseada nas SPDE pode ser considerada um método de aproximação de "alto nível", pois a matriz de precisão é esparsa e, como dito anteriormente, reduz os custos computacionais mesmo que usando diversas funções base como observações. A grande vantagem em se usar esta metodologia está na redução dos custos computacionais, contudo, retira certa flexibilidade na escolha da função de covariância, porque limita-se à função de covariância de Matérn.

\subsection{ICAR: Um caso especial do SPDE}

De acordo com o Lindgren, Rue e Lindström (2011), da equação (4.1) quando $\kappa=0$, o espaço de Hilbert é um espaço de classes de equivalência de funções, correspondentes às soluções SPDE onde funções arbitrárias no espaço nulo de $(-\Delta)^{\alpha / 2}$ podem ser adicionadas. Tais campos de solução são conhecidos como campos intrínsecos e têm propriedades bem definidas. Com trechos de funções em base linear, o modo intrínseco pode ser exatamente reproduzido para $\alpha=1$.

A noção de convergência de espaço não nulo permitiu aos autores formular uma simples prova do resultado de Besag e Mondal (2005), que diz que a $1^{a}$ ordem intrínseca do modelo CAR nas infinitas grades no $R^{2}$ convergem para o processo de de Wijs, que é uma generalização intrínseca de um campo aleatório Gaussiano. No apêndice A.1 de Lindgren, Rue e Lindström (2011) é possível notar que para $\alpha=1$ e $\kappa=0$, a Matriz Q para uma malha regular triangular coincide com o modelo CAR intrínseco de $1^{o}$ ordem. O espaço nulo da metade Laplaciana é função constante. Isso mostra que o modelo padrão CAR, visto como uma representação do espaço de Hilbert com funções de base linear, convergem para o processo de de Wijs, que é um caso especial de SPDE com $\alpha=1, \kappa=0$ no $R^{2}$.

\subsection{Inferência Bayesiana}

Nesta seção, apresentaremos o modelo Bayesiano hierárquico, que será útil na metodologia utilizada no trabalho. Esta formulação hierárquica possibilita mecanismos de inferência Bayesiana através de aproximações analíticas de Laplace (INLA). Apresentaremos abaixo alguns conceitos básicos de inferência Bayesiana necessários para a compreensão do que foi realizado neste trabalho.

\subsubsection{Modelo Bayesiano hierárquico}

Considere que tenhamos uma amostra aleatória $y=\left(y_{1}, y_{2}, \ldots y_{n}\right)$, isto é, os dados são independentes e identicamente distribuídos e queremos modelar os dados a partir de uma dada distribuição em que a função de verossimilhança é $p(y \mid \theta)$. Considere ainda que 
$\theta$ seja um vetor de parâmetros desconhecidos com uma distribuição a priori $p(\theta)$. Usando o teorema de Bayes, temos:

$$
p(\theta \mid y)=\frac{p(y \mid \theta) p(\theta)}{p(y)}
$$

em que

$$
p(y)=\int p(y \mid \theta) p(\theta) d \theta
$$

Sabemos que $p(y)$ é constante em relação a $\theta$. Assim, conseguimos chegar na distribuição a posteriori $p(\theta \mid y)$ :

$$
p(\theta \mid y) \propto p(y \mid \theta) p(\theta)=p(\theta) \prod_{i=1}^{n} p\left(y_{i} \mid \theta\right)
$$

A distribuição a posteri é muito útil pois combina a informação prévia que tínhamos sobre o vetor de parâmetros $\theta$, representada pela distribuição a priori $p(\theta)$, com a informação dos dados y, contidas na função de verossimilhança $p(y \mid \theta)$.

Realizaremos a inferência do vetor dos parâmetros $\theta$ com base na distribuição a posteriori $p(\theta \mid y)$. É possível fazer predição de observações futuras z após observar os dados de y, dependerá da distribuição a posteriori, em que a densidade preditiva para z dado y é dada por

$$
f(z \mid y)=\int f(z \mid y, \theta) p(\theta \mid y) d \theta
$$

Como z e y são condicionalmente independentes dado $\theta$, chegamos que a equação (4.18) pode ser reescrita como

$$
f(z \mid y)=\int f(z \mid \theta) p(\theta \mid y) d \theta
$$

Considere que possamos decompor $\theta$ da seguinte forma:

$$
p(\theta)=\int p(\theta \mid \lambda) p(\lambda) d \lambda
$$

em que $\lambda$ é o vetor de hiperparâmetros e $p(\lambda)$ a distribuição. Este modelo com uma estrutura hierárquica na distribuição priori, $p(\theta)$, é chamado de modelo bayesiano hierárquico.

Paulino, Turkman e Murteira (2003) dizem que esta decomposição ajuda na distribuição a priori, sendo normalmente usado pela dificuldade em quantificar exatamente a informação a priori e pela importância em adicionar a incerteza decorrente sobre os hiperparâmetros. 
Na implementação do modelo deste trabalho, será necessário usar a estrutura hierárquica, pois ela permite o uso de métodos de inferência Bayesiana baseado nas aproximações de Laplace seqüenciais que foram propostas por Rue, Martino e Chopin (2009), sendo assim, a distribuição a posteriori pode ser representada por:

$$
p(\theta, \lambda \mid y) \propto p(y \mid \theta, \lambda) p(\theta \mid \lambda) p(\lambda)=p(\theta \mid \lambda) p(\lambda) \prod_{i=1}^{n} p\left(y_{i} \mid \theta, \lambda\right)
$$

sendo $y_{i} \mid \theta, \lambda, i=1, \ldots, n$, independentes e identicamente distribuídos.

De acordo com Clark e Gelfand (2006), a especificação do modelo nessa forma hierárquica é vantajosa pois podemos ter modelos mais complexos a partir de relações condicionais simples, da mesma forma que não é necessário que os dados sejam independentes, pois a independência condicional já é suficiente. Os autores também destacam que as distribuições posteriori podem apresentar dimensões elevadas e podem ser analiticamente intratáveis, motivando o uso de aproximações como Monte Carlo via Cadeias de Markov (MCMC: Markov Chain Monte Carlo) ou pelas aproximações aninhadas de Laplace (do inglês, Integrated Nested Laplace Approximations - INLA).

\subsubsection{Modelos dinâmicos usando INLA}

Na obtenção de resultados para a posteriori de interesse, geralmente precisamos resolver integrais Bayesianas que não apresentam solução analítica. Nos últimos anos, uma das principais abordagens para contornar esta dificuldade era recorrer aos métodos de Monte Carlo via Cadeias de Markov (MCMC: Markov Chain Monte Carlo). De forma bem simplificada, este método usa amostras obtidas através de simulações de cadeias de Markov para aproximar as integrais das distribuições. Contudo, os custos operacionais com o MCMC são muito elevados para o caso de modelos espaço-temporais como mostrado em Rue, Martino e Chopin (2009).

O uso do INLA é justificado pois ele se baseia em aproximações determinísticas em que são feitas inferências de uma forma ágil e com exatidão, através dos modelos Gaussianos Latentes. Estes modelos são um subconjunto dos modelos Bayesianos, em que o preditor depende de um campo aleatório Gaussiano latente.

Como dito na introdução da seção, o método que será utilizado para realizar o procedimento de estimação Bayesiana é o mesmo proposto em Rue, Martino e Chopin (2009). As Aproximações Aninhadas Integradas de Laplace (INLA), como definido pelos autores, é uma abordagem recente para realizar a inferência Bayesiana completa e rápida através da aproximação precisa das densidades marginais posteriores de hiperparâmetros e variáveis latentes em modelos gaussianos latentes. 
Para mostrar os detalhes principais deste método, apresentamos os passos fundamentais nesta seção. O método INLA permite aproximar a distribuição posterior dos parâmetros e fatores latentes em modelos hierárquicos utilizando a representação dada por:

$$
\begin{array}{r}
\pi\left(\xi_{i} \mid Y\right)=\int \pi\left(\xi_{i} \mid \theta, Y\right) \pi(\Theta, Y) d \theta \\
\pi\left(\theta_{j}, Y\right)=\int \pi(\theta, Y) d \theta_{j}
\end{array}
$$

sendo $\xi$ os fatores latentes e $\theta$ o vetor de hiperparâmetros. Para chegar nesta aproximação, é necessário realizar sequências de aproximações analíticas baseadas em métodos de Laplace para as distribuições condicionais do vetor de hiperparâmetro e dos fatores latentes.

Inicialmente, faz-se uma aproximação para $\pi(\xi \mid Y, \theta)$ usando uma distribuição multivariada Gaussiana $\tilde{\pi}_{G}(\xi \mid Y, \theta)$. Utilizando de uma aproximação de Laplace e com base na aproximação inicial, a distribuição posteriori é então:

$$
\left.\tilde{\pi}(\Theta \mid Y) \propto \frac{\pi(\xi \mid \theta, Y)}{\tilde{\pi}_{G}(\xi \mid \theta, Y)}\right|_{\xi=\xi^{*}(\Theta)}
$$

$\operatorname{com} \xi^{*}(\theta)$ representado na moda da distribuição condicional de $(\xi \mid \theta)$. Para encontrar o resultado desta moda é necessário utilizar um método de busca de raízes baseados no algoritmo de Newton-Raphson. Aplica-se a aproximação de Laplace para as condicionais $\pi\left(\xi_{i} \mid \theta, Y\right)$ para a sequência de hiperparâmetros $\theta$. Usando a aproximação de Laplace, conseguimos chegar agora nas distribuições posteriores dos fatores latentes:

$$
\left.\tilde{\pi}_{L A}\left(\xi_{i} \mid \theta, Y\right) \propto \frac{\pi(\xi, \Theta, Y)}{\tilde{\pi}_{G}}\left(\xi_{-i} \mid \xi_{i}, \Theta, Y\right)\right|_{\xi_{-i}=\xi_{-i}^{*}\left(\xi_{i}, \Theta\right)}
$$

sendo $\xi_{-i}$ os fatores latentes $\xi$ com o $i$-ésimo elemento omitido, sendo $\tilde{\pi}_{G}\left(\xi_{-i} \mid \xi_{i}, \Theta, Y\right)$ uma aproximação Gaussiana de $\pi\left(\xi_{-i} \mid \xi_{i}, \Theta, Y\right)$ mantendo $\xi_{i}$ fixo e $\xi_{-i}^{*}\left(\xi_{i}, \Theta\right)$ na moda de $\pi\left(\xi_{-i} \mid \xi_{i}, \Theta, Y\right)$. Por fim, combinaremos as duas aproximações citadas anteriormente e integramos os fatores irrelevantes. Sendo assim, chegamos na distribuição marginal posterior dos fatores latentes:

$$
\pi\left(\xi_{i} \mid Y\right)=\int \pi\left(\xi_{i} \mid \Theta, Y\right) \pi(\Theta, Y) d \theta \approx \int \tilde{\pi}\left(\theta_{k} \mid Y\right) d \theta_{-i}
$$

De forma análoga, encontraremos a distribuição marginal posterior dos hiperparâmetros:

$$
\pi\left(\theta_{j} \mid Y\right)=\int \pi(\theta \mid Y) d \theta_{-i} \approx \int \tilde{\pi}\left(\theta_{k} \mid Y\right) d \theta_{-i}
$$

Rue, Martino e Chopin (2009) mostraram que essas aproximações são bastante acuradas e computacionalmente eficientes, quando aplicados a campos aleatórios Gaus- 
sianos latentes com matriz de precisão esparsa e com um número não muito grande de hiperparâmetros. Discussões sobre propriedades e aplicações da metodologia INLA podem ser encontradas em Rue et al. (2017) e aplicações em modelos espaciais em Bakka et al. (2018).

\section{Dados}

Para a base de dados do projeto de pesquisa serão utilizadas informações sobre os preços dos imóveis, características internas - como número de dormitórios, banheiros, garagem, elevador e unidades por andar -, e as características externas, como a distância para o comércio e serviços: transporte público (Metrô e CPTM), educação (Unidades escolares) e saúde (Unidade Básica de Saúde). Além destas variáveis de distância, incluímos no nosso modelo a distância até as favelas ou loteamentos clandestinos e irregulares de baixa renda. Todas essas informações são disponibilizadas na base de dados do Centro de Estudos da Metrópole (CEM). Nesta base, teremos acesso ao valor dos lançamentos imobiliários na cidade de São Paulo, sistematizadas pela Empresa Brasileira de Patrimônio (Embraesp), sendo que analisaremos o período de 2000 até 2013.

Em relação à base de dados, destaca-se o fato de se utilizar dados georreferenciados, que descrevem fenômenos geográficos cuja localização está associada a uma posição sobre a superfície terrestre. Com esta base, temos informações de coordenadas de latitude e longitude dos lançamentos imobiliários, bem como das diversas características de localidade do imóvel, como proximidade com comércio, transportes, entre outros.

Pode-se ver na Figura 5.1 o mapa com os lançamentos imobiliários na região da cidade de São Paulo. Cada ponto preto do mapa corresponde a um lançamento em uma determinada coordenada geográfica para uma data específica. Visualmente, nota-se uma concentração dos lançamentos imobiliários nas zonas central, norte e oeste da cidade.

Além dos dados georreferenciados do CEM, utilizou-se a base de dados estatísticos georreferenciados da Prefeitura de São Paulo. Desta base, foram criadas outras duas variáveis de distância: distância a represa de Guarapiranga e a represa de Billings. Adicionalmente, empregou-se a fonte de dados da SEADE (Sistema Estadual de Análise de Dados), na qual gerou-se a variável de crime violento (número de atos que resultam em conflito, lesão física grave ou morte).

Para identificar o impacto da renda no nosso modelo, utilizamos a renda domiciliar per capita extraída dos Censos demográficos de 2000 e 2010. A vantagem de se utilizar os dados do censo é a possibilidade em desagregar mais a informação, tendo elas por distrito censitário. A desvantagem em utilizar estes dados é a escassez nos anos em que não houve a pesquisa do Censo. Para amenizar esta adversidade, corrigiu-se a variável através do 
Figura 5.1 - Mapa de Lançamentos Imobiliários.

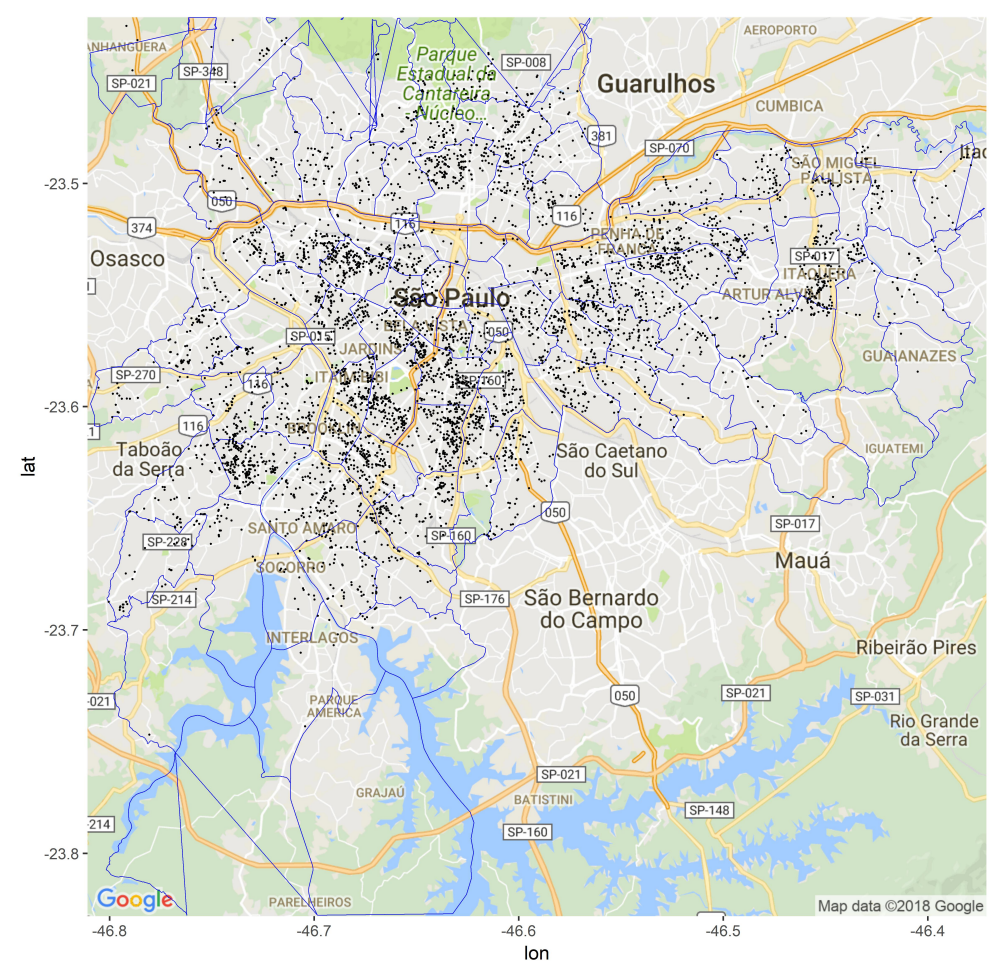

principal índice de inflação, IPCA (Índice Nacional de Preços ao Consumidor Amplo) para os anos sem realização do censo. Os dados tem como referência o ano base de 2010.

Uma forma de contornar a falta de dados do Censo foi incluir a variável de luminosidade noturna, conhecida como DMSP-OLS Nighttime Lights Time Series, gerada a partir de dados calibrados do National Geophysical Data Center (NDGC), para um melhor entendimento de como a variável de luminosidade foi gerada, ver Laurini (2016b). Combinar as informações da renda proveniente do Censo com a luminosidade noturna do NGDC podem contribuir para solucionar esta dificuldade, pois é intuitivo que as luzes noturnas devem refletir a atividade econômica em algum grau, já que a luz é um insumo críticos em diversos processos de produção e consumo. Esta variável também é uma medida de infraestrutura e urbanização, e por isso tem poder explicativo sobre os preços de imóveis. A Figura 5.2b mostra a mensuração de luminosidade noturna para os anos de 2000 e 2013, para a região analisada neste trabalho. Limitações sobre o uso desta variável em análise de renda podem ser encontradas em Laurini (2016b), sendo que a principal é a saturação da medida em áreas densamente povoadas.

Através da Tabela 5.1 é possível ver as estatísticas descritivas das variáveis utilizadas no modelo.

A descrição das variáveis são: 'x' e 'y' representam as coordenadas das nossas observações, sendo respectivamente a longitude e latitude, já 'tipo' refere-se ao tipo de empreendimento podendo ele ser horizontal (casa) ou vertical (prédio). A variável 
Figura 5.2 - Iluminação Noturna - Cidade de São Paulo.

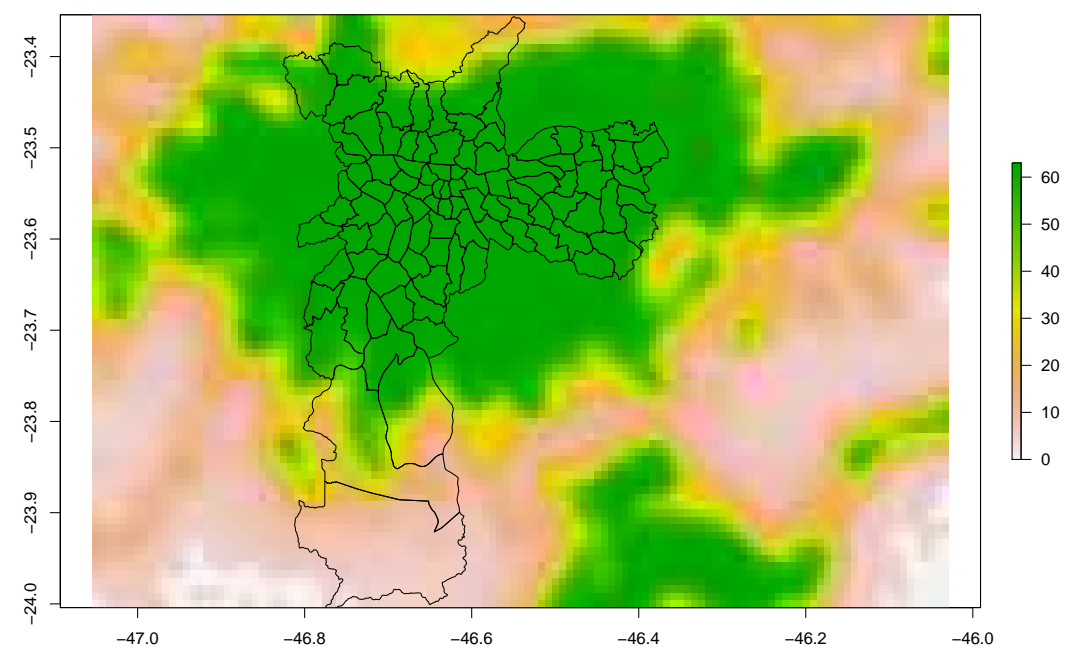

(a) DMSP-OLS Nighttime Lights Time Series - 2000

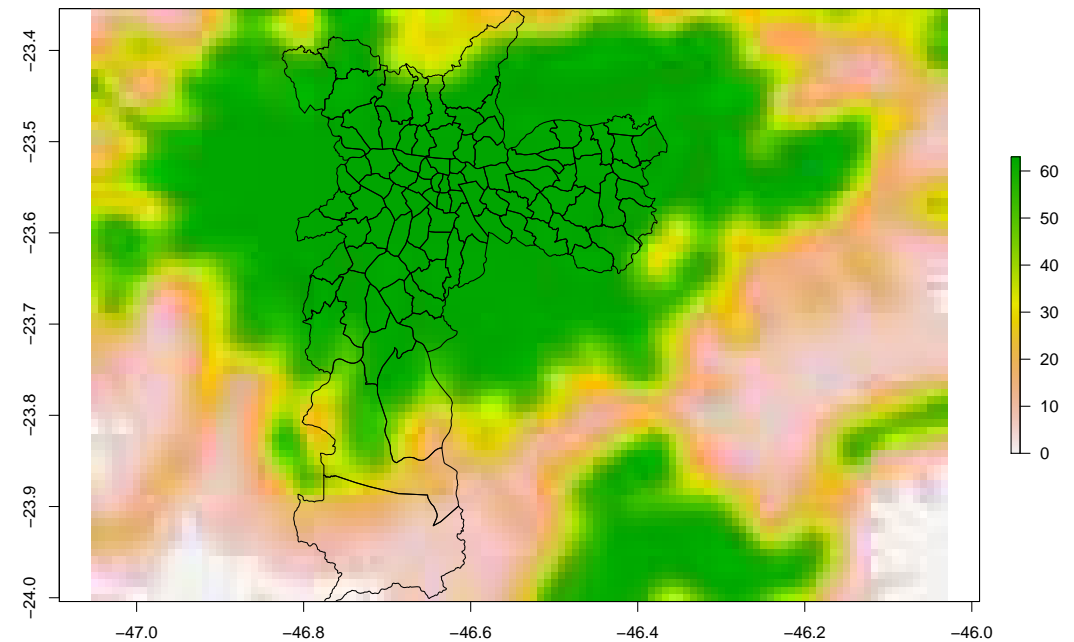

(b) DMSP-OLS Nighttime Lights Time Series - 2013

'ano', refere-se ao ano de lançamento, 'dormitório', 'elevador', 'banheiro' e 'garagem' são respectivamente as quantidades que cada domicílio tem das respectivas variáveis. 'Uniandar' é o número de unidades por andar. 'Renda' corresponde ao valor da renda per capita para um determinado distrito censitário e 'crime' quantifica o número de óbitos por agressões (homicídio) ocorridos em cada região censitária.

As variáveis que mensuram a distância do lançamento imobiliário até as respectivas localidades mais próximas são:

'dmetro' - distância até a estação mais próxima do metrô;

'dcptm' - distância até a estação de trem mais próxima; 
Tabela 5.1 - Estatísticas Descritivas

\begin{tabular}{ccccccc}
\hline & Mínimo & $0.025 q$ & Mediana & Média & $0.975 q$ & Máximo \\
\hline $\mathrm{x}$ & -46.81 & -46.69 & -46.65 & -46.64 & -46.59 & -46.38 \\
$\mathrm{y}$ & -23.75 & -23.61 & -23.57 & -23.57 & -23.53 & -23.41 \\
Tipo & 1.00 & 2.00 & 2.00 & 1.81 & 2.00 & 2.00 \\
Dormitório & 1.00 & 2.00 & 3.00 & 2.6999 & 3.00 & 6.00 \\
Banheiro & 1.00 & 1.00 & 2.00 & 2.033 & 2.00 & 6.00 \\
Elevador & 0.00 & 0.00 & 2.00 & 1.815 & 3.00 & 26.00 \\
Garagem & 0.00 & 1.00 & .002 & 1.986 & 2.00 & 12.00 \\
Uniandar & 0.00 & 1.00 & 4.00 & 3.932 & 6.00 & 60.00 \\
Iluminação & 39.00 & 63.00 & 63.00 & 62.85 & 63.00 & 63.00 \\
Renda & 0.213 & 1.269 & 2.33 & 3.42 & 4.56 & 30 \\
dmetro & 0.02 & 1.21 & 2.63 & 3.75 & 4.5 & 23.00 \\
dcptm & 0.07 & 1.53 & 2.60 & 3.00 & 4.00 & 11.00 \\
dfavela & 1199 & 1221 & 1227 & 1226 & 1231 & 1243 \\
descola & 0.01 & 0.23 & 0.35 & 0.40 & 0.52 & 1.60 \\
dubs & 0.01 & 0.50 & 0.78 & 0.84 & 1.10 & 2.60 \\
colormap & 0.00 & 0.00 & 0.00 & 0.02 & 0.00 & 1.00 \\
crime & 0.76 & 5.75 & 11.12 & 15.35 & 19.24 & 118.31 \\
dguarapiranga & 0.17 & 9.75 & 14.60 & 15.50 & 21.00 & 40.00 \\
dbillings & 0.24 & 10.77 & 15.60 & 15.80 & 20.00 & 36.00 \\
Precom2 & 559.7 & 2143.9 & 2787.7 & 3152.0 & 3778.8 & 13707.2 \\
ano & 2000 & 2004 & 2007 & 2007 & 2010 & 2013 \\
n & 7721 & & & & & \\
\hline
\end{tabular}

'descola' - distância até a unidade escolar mais próxima, independente do tipo de ensino (particular ou pública) ou do nível escolar. Na Figura 5.3 é possível verificar as escolas públicas e privadas georreferenciadas. Neste mapa, é possível notar visualmente um maior número de unidades escolares na zona leste da cidade;

'dubs' - distância até um ambulatório, hospital, Unidades Básicas de Saúde (UBS) e ambulatórios de especialidades, na figura 5.4 é possível notar os locais em que há Unidades Básicas de Saúde. Neste mapa é possível notar, visualmente, uma distribuição das UBS de forma mais uniforme;

'dfavela' - distância até favelas e loteamentos clandestinos e irregulares de baixa renda, na figura 5.5 é possível notar como foi gerado o georreferenciamento da variável favela, cada ponto no mapa corresponde ao centro geométrico dos polígonos representantes dos respectivos loteamentos e favelas;

'dguarapiranga' - distância até a represa de guarapiranga;

'dbillings' - distância até a represa de billings.

'colormap' é um controle para área povoada, sendo uma dummie baseada no mapeamento aéreo da região. Caso seja 1 a região é não povoada (por exemplo havia mata) e 0 em caso contrário. 'Iluminação' é a intensidade luminosa da região vista a noite, e.g. Figura 5.2b. Por fim, a variável dependente do nosso modelo 'precom2', que é Preço por 
Figura 5.3 - Mapa de Escolas.

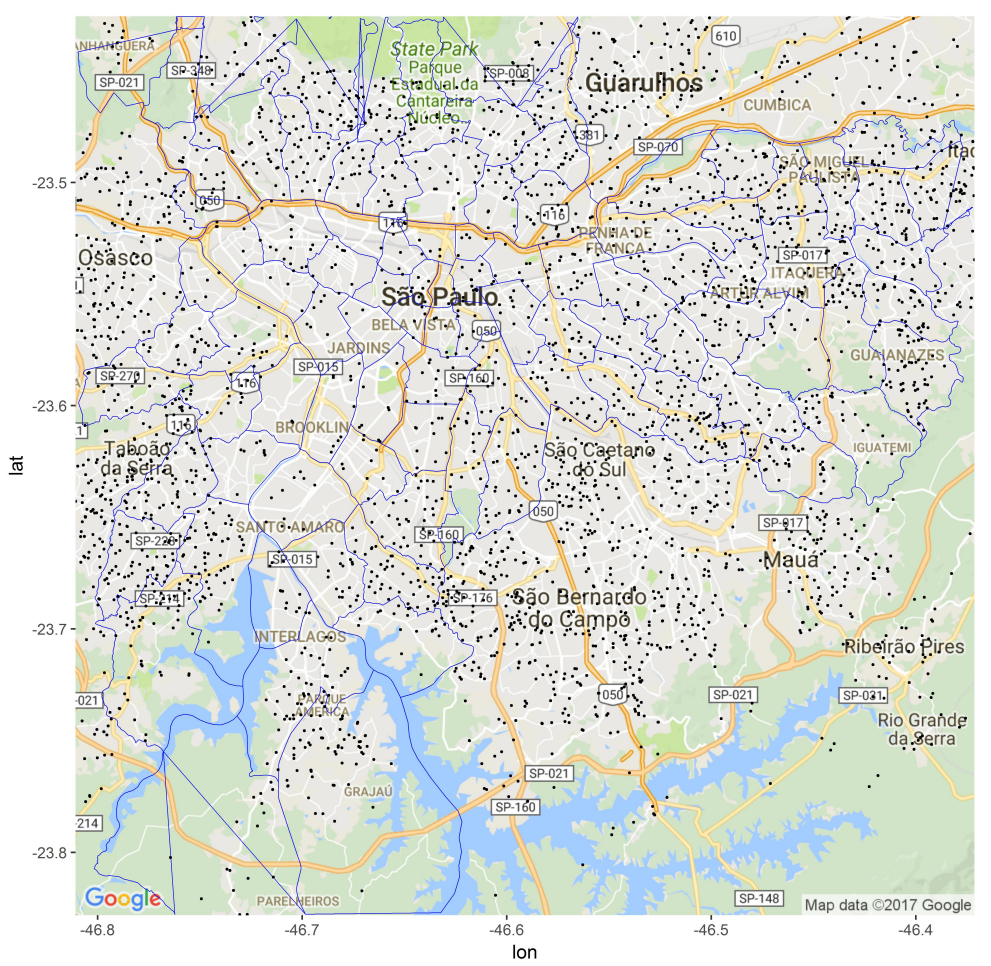

Figura 5.4 - Mapa de Unidade Básica de Saúde.

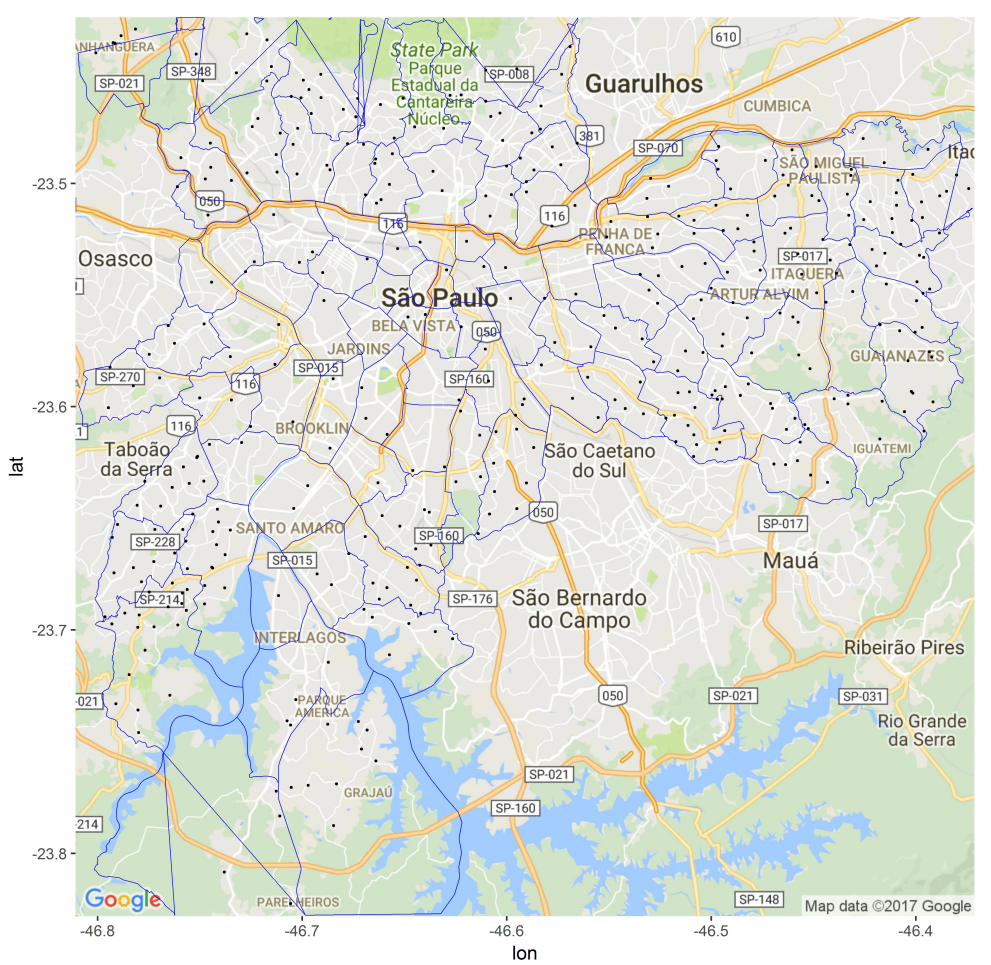

$m^{2}$ da área total da unidade (em $\mathrm{R} \$$ ) em valores de dezembro de 2013 pelo IGP-DI.

A Figura 5.6 mostra os valores observados nesta amostra para o preço do metro quadrado ao longo dos anos e também a cada período (mês) da amostra. Através desta 
Figura 5.5 - Mapa de Favelas e loteamentos.

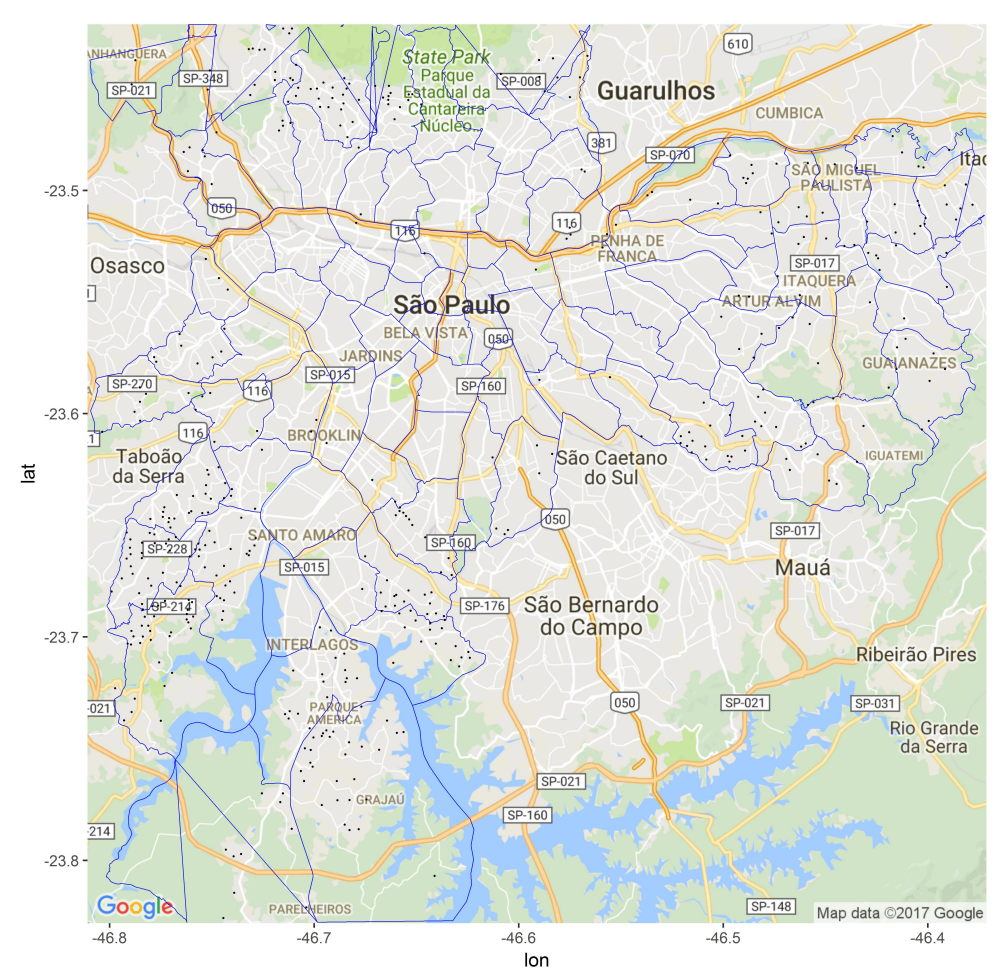

Figura 5.6 - Gráfico do Preço por metro quadrado
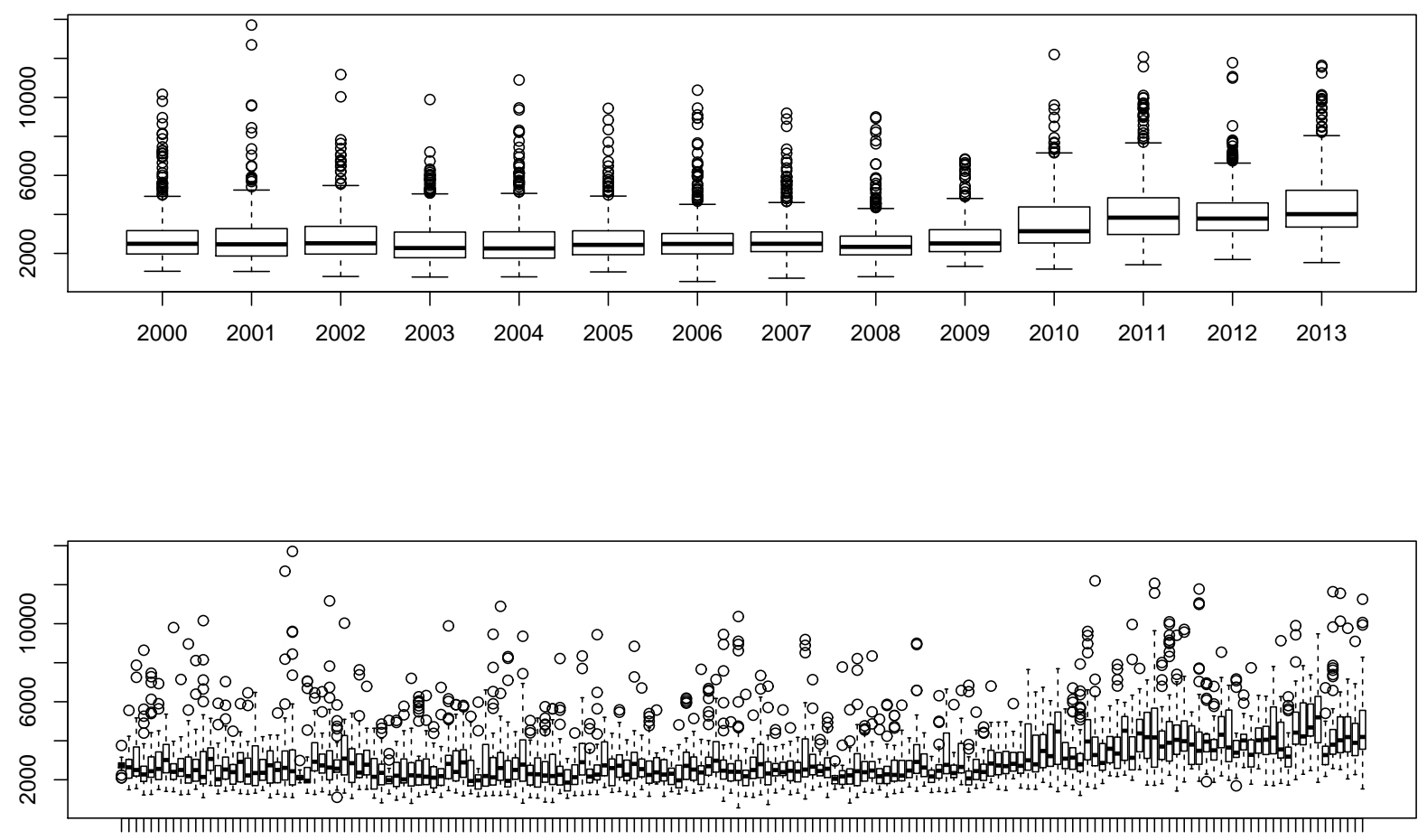

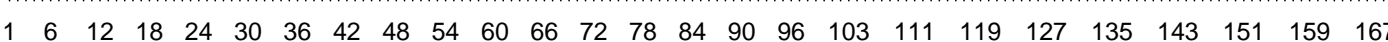


figura é possível ter uma intuição de que esta série tem uma componente de tendência. É possível identificar esta componente quando olhamos para a posição central dos dados (mediana). Como em alguns casos, a linha da mediana no retângulo está próxima da parte de baixo verificamos que os dados são positivamente assimétricos. Também é possível notar os outliers em forma de pontos fora da linha desenhada. Bem como, é possível notar uma mudança nas cauda da distribuição (comprimento das linhas) depois do ano de 2008.

\section{Resultados}

Como explicado anteriormente, para modelar o preço do metro quadrado dos lançamentos, utilizaremos uma estrutura em que iremos decompor o preço do metro quadrado $y(s, t)$ em quatro fatores principais: efeitos de covariadas, tendência $\left(\mu_{t}\right)$, ciclo $\left(c_{t}\right)$ e efeitos aleatórios espaciais $\left(\xi_{t}\right)$, utilizando a estrutura de modelagem detalhada nas Seções anteriores. Serão analisadas diversas especificações para o processo de preços partindo de um modelo hedônico simples (sem componentes de tendência, ciclo e espaciais) até modelos cujos efeitos aleatórios espaciais são variantes no tempo. Em todos estes modelos realizamos a estimação Bayesiana usando a metodologia INLA, descrita anteriormente.

Os efeitos esperados por trabalhos anteriores das varáveis escolhidas estão expostos na Seção 3. Os parâmetros utilizados no nosso modelo dividem-se em dois grupos: efeitos fixos e variáveis. O grupo de efeito fixo foi separado em dois grupos principais, uma das características intrínsecas do imóvel e outro para as características extrínsecas (variáveis espaciais). Dentro do grupo das características intrínsecas, temos os efeitos das variáveis explicativas como dormitórios, número de vagas de garagem, número de banheiros, número de elevador e número de unidades por andar. Já para o grupo que corresponde às variáveis espaciais, temos um subgrupo correspondente à distância para alguns serviços, como a distância às estações de metrô e de trem, distância a escolas e Unidades Básicas de Saúde. Acreditamos que a proximidade de um lançamento imobiliário com estes serviços tenderia a aumentar o preço do metro quadrado da unidade. Um outro subgrupo corresponde a localidades específicas que poderiam valorizar o imóvel, como a distância até as represas de Guarapiranga e Billings, ou desvalorizar o imóvel como a distância até uma favela. Outras variáveis do nosso modelo correspondem ao tipo do empreendimento, sendo ele do tipo 1 se o imóvel é vertical (prédio) e tipo 2 se é residencial. Em relação à variável Crime, esperamos que em localidades com maior incidência de crimes violentos haja uma relação negativa entre Crime e a variável dependente, pois como foi dito na Introdução, a habitação provê segurança, se uma habitação está localizada em uma área de risco, essa sensação de segurança é mitigada, e acreditamos que possa influenciar diretamente no preço do imóvel. Em Tita, Petras e Greenbaum (2006), os autores identificaram esta mesma relação entre as variáveis, porém, eles acreditam que o crime é capitalizado a taxas 
diferentes para bairros pobres, de classe média e ricos e concluem que o crime violento é o que dá o maior custo, ou seja, em locais com maior incidência de crimes violentos, o preço do imóvel é menor. Para a variável Renda, que representa a renda per capita, espera-se que seja fundamental no modelo, como foi identificado em Holly, Pesaran e Yamagata (2010). Os autores encontraram significância para os níveis de dependência espacial entre a renda real e o preço real imobiliário.

Os modelos propostos são analisados em grau crescente de complexidade. Primeiro, apresentamos os modelos sem componentes latentes e depois modelos com componentes dinâmicos e efeitos aleatórios espaciais constantes no tempo e finalmente modelos onde os efeitos aleatórios espaciais também apresentam uma estrutura dinâmica.

\subsection{Modelos sem componentes latentes}

A Tabela 6.1 apresenta o resultado da estimação de um modelo puramente composto de componentes hedônicos, sem a inclusão dos componentes dinâmicos e espaciais, para o conjunto completo de covariadas analisadas nesse trabalho. Note que em todas os modelos nós analisamos o preço por metro quadrado em milhares de unidades, para evitar problemas de escala nas estimações, e assim os efeitos marginais devem ser analisados nessa unidade. Nos gráficos apresentamos os resultados na escala de preço normal. Nessa parametrização encontramos efeitos positivos e relevantes (o intervalo de credibilidade não inclui o zero) do número de vagas de garagem, unidades por andar, tipo de empreendimento, iluminação noturna e distância à escola, e efeitos negativos para número de dormitórios, número de elevadores, renda, crime, distâncias a CPTM, a favela e a represa de Guarapiranga sobre o preço por $m^{2}$. No entanto, esse modelo apresenta problemas de interpretação em relação a renda - nesse modelo a renda per capita tem efeito negativo sobre o preço, que é um efeito inesperado. Outro problema é que o ajuste do modelo é bastante inferior aos demais modelos com a inclusão de componentes de tendência, ciclo e espaciais, como será mostrado pela comparação de ajuste: Verossimilhança marginal e critérios DIC e WAIC. Mostraremos esses resultados a seguir.

\subsection{Modelos com efeitos aleatórios espaciais fixos no tempo}

Na primeira classe de especificações incluindo efeitos aleatórios espaciais assumimos que estes efeitos são constantes no tempo, ou seja, o efeito aleatório espacial tem o mesmo impacto em cada período no modelo, e a variação dinâmica é controlada pelos possíveis componentes de tendência e ciclo.

Para realizar os procedimentos de inferência para os modelos com efeitos espaciais usando o método proposto na Seção 4 foi feita uma triangulação de Delaunay para a 
Tabela 6.1 - Resultados - Estimação do modelo sem efeitos aleatórios

\begin{tabular}{ccccccc}
\hline & média & $\mathrm{dp}$ & $.025 \mathrm{q}$ & $.5 \mathrm{q}$ & $.975 \mathrm{q}$ & moda \\
\hline Dormitório & -0.7201 & 0.0250 & -0.7693 & -0.7201 & -0.6710 & -0.7201 \\
Garagem & 0.4343 & 0.0192 & 0.3965 & 0.4343 & 0.4720 & 0.4343 \\
Banheiro & 0.5757 & 0.0306 & 0.5156 & 0.5757 & 0.6356 & 0.5757 \\
Elevador & -0.0598 & 0.0078 & -0.0751 & -0.0598 & -0.0445 & -0.0598 \\
Unid. Andar & 0.0508 & 0.0054 & 0.0403 & 0.0508 & 0.0613 & 0.0508 \\
Empreend. Horizontal & 23.1952 & 7.4783 & 8.5128 & 23.1950 & 37.8654 & 23.1952 \\
Empreend. Vertical & 23.2489 & 7.4787 & 8.5657 & 23.2487 & 37.9198 & 23.2489 \\
Iluminação & 0.0646 & 0.0191 & 0.0271 & 0.0646 & 0.1020 & 0.0646 \\
Renda & -0.0223 & 0.04777 & -0.0317 & -0.0223 & -0.01301 & -0.0223 \\
Dist. Metrô & -0.0315 & 0.0054 & -0.0422 & -0.0315 & -0.0208 & -0.0315 \\
Dist. CPTM & -0.0702 & 0.0079 & -0.0856 & -0.0702 & -0.0547 & -0.0702 \\
Dist. Favela & -0.0190 & 0.0059 & -0.0307 & -0.0190 & -0.0074 & -0.0190 \\
Dist. Escola & 0.5027 & 0.0601 & 0.3847 & 0.5027 & 0.6206 & 0.5027 \\
Dist. Ubs & 0.0192 & 0.0317 & -0.0430 & 0.0192 & 0.0813 & 0.0192 \\
Crime & -0.0286 & 0.0010 & -0.0305 & -0.0286 & -0.0267 & -0.0286 \\
Colormap & -0.5589 & 0.0978 & -0.7509 & -0.5589 & -0.3671 & -0.5589 \\
Dist. Rep. Guarapiranga & -0.0396 & 0.0137 & -0.0665 & -0.0396 & -0.0128 & -0.0396 \\
Dist. Rep. Billings & 0.0174 & 0.0123 & -0.0068 & 0.0174 & 0.0416 & 0.0174 \\
Precisão Gaussiana & 0.8049 & 0.013 & 0.7797 & 0.8048 & 0.8307 & 0.8047 \\
Marginal Lik & -11936.74 & & & & & \\
DIC & 23606.61 & & & & & \\
WAIC & 23609.21 & & & & & \\
\hline
\end{tabular}

${ }^{1}$ Nota: Valores das variável dependente e das covariadas renda medidas em milhares de Reais

construção do mesh de aproximação do contínuo espacial. Essa metodologia permite introduzir algumas restrições importantes para um melhor comportamento na estimação, como maximizar o comprimento dos lados e minimizar os ângulos dos triângulos. Com isso, é possível garantir uma transição entre os pequenos e grandes triângulos de uma forma mais suave (ver Berg et al. (2008)).

A malha triangulada utilizada neste trabalho é apresentada na Figura 6.1 e representa uma aproximação do espaço da cidade de São Paulo. Note que a malha também requer uma área externa, o que é necessário para evitar problemas de borda em aproximações numéricas, como discutido em Lindgren, Rue e Lindström (2011). A construção da malha envolve um tamanho de triângulo ideal que considera o número e a distribuição dos pontos observados e o custo computacional envolvido na aproximação. O tamanho escolhido permite uma aproximação adequada do processo espacial contínuo. Nós tentamos outras especificações e os resultados são robustos para a escolha da malha.

Os resultados da estimação do modelo com todas as covariadas, componentes de tendência, ciclo e espacial estão apresentados na Tabela 6.2, em que são apresentadas as estimativas Bayesianas a posteriori e os respectivos intervalos de credibilidade para as características estudadas.

As variáveis elevador, unidades por andar, empreendimento vertical, empreendi- 


\section{Constrained refined Delaunay triangulation}

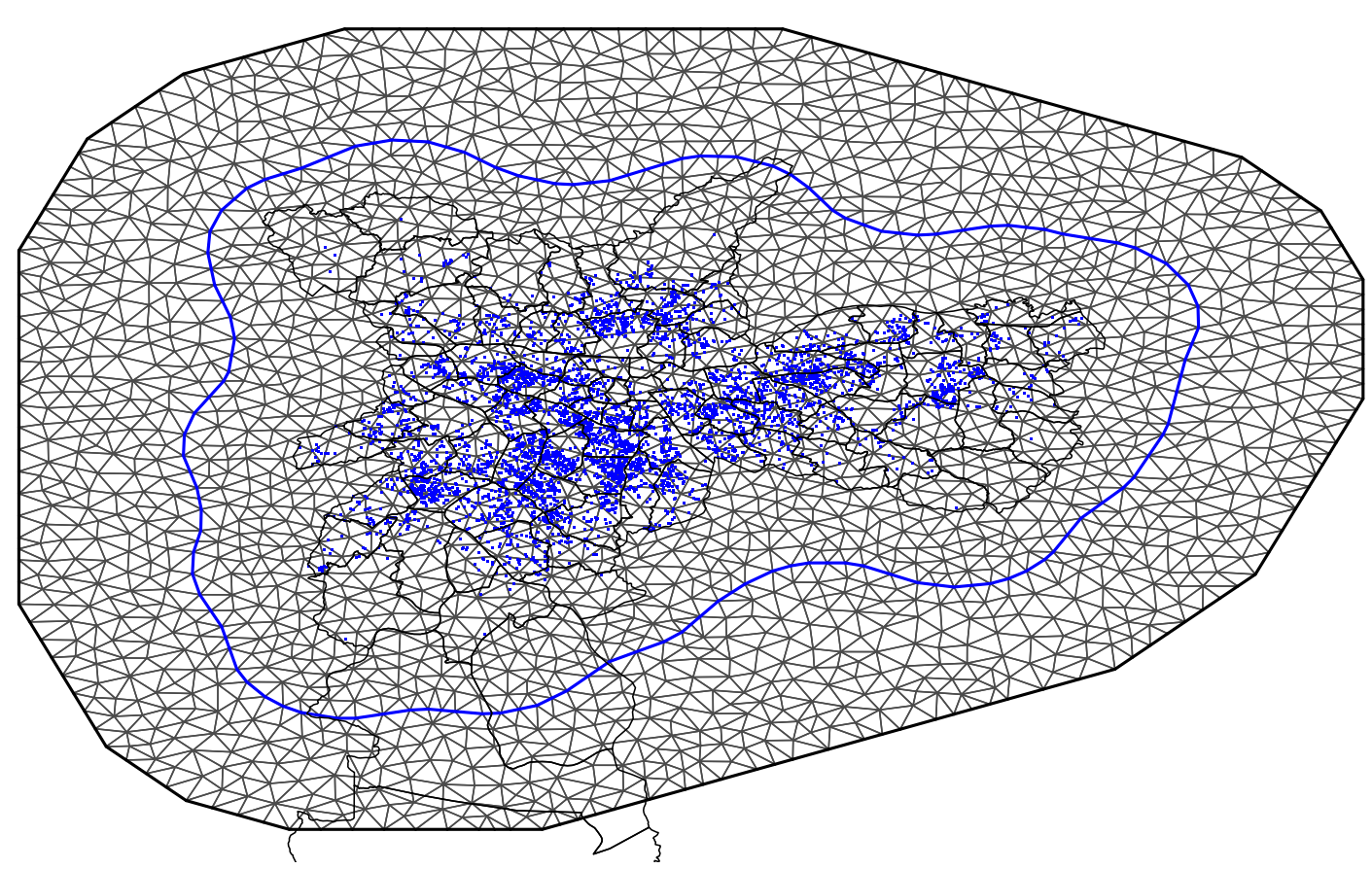

Figura 6.1 - Triangulação de Mesh e lançamentos imobiliários

mento horizontal, renda, distância à favela e distância à escola não apresentaram evidência significativa, uma vez, que os seus respectivos intervalos de credibilidade $95 \%$ contém o valor zero. Devido a estes componentes com problemas de efeito, nós realizamos alguns procedimentos de seleção de modelos. Nós utilizamos duas formas para determinar o modelo mais parcimonioso. A primeira é baseada em uma análise análoga a significância clássica onde especificamos a participação do zero a partir da presença ou não de zero nos respectivos intervalos de $95 \%$ de credibilidade. Também utilizamos critérios de informação Bayesianos, em especial o DIC ("Deviance Information Criterion") e ao WAIC ("WatanabeAkaike Information Criterion"). O DIC é um critério para a seleção de modelos Bayesianos muito popular que foi introduzido por Spieglhalter et al. (2002)), já o WAIC por Watanabe (2010). Uma discussão mais aprofundada é feita em Gelman, Hwang e Vehtari (2014), em que os autores explicam que o WAIC tem a propriedade desejável de calcular a média sobre a distribuição posterior, em vez de condicionar em uma estimativa pontual, como é feito no DIC. Isso é especialmente relevante em um contexto preditivo, já que o WAIC está avaliando as previsões que estão realmente sendo usadas para os novos dados em um contexto Bayesiano. De acordo com ambos os critérios, prefere-se o modelo com o menor valor. Em nossas análises os resultados do DIC e WAIC foram consistentes. A partir da exclusão das variáveis sem significância estatística, chegamos ao modelo final exposto na 
Tabela 6.2 - Resultados - Estimação do modelo Completo

\begin{tabular}{|c|c|c|c|c|c|c|}
\hline & média & $\mathrm{dp}$ & $.025 q$ & $.5 q$ & $.975 q$ & moda \\
\hline Dormitório & -0.1405 & 0.0168 & -0.1734 & -0.1405 & -0.1076 & -0.1405 \\
\hline Garagem & 0.0127 & 0.1810 & 0.2059 & 0.2309 & 0.2059 & 0.0127 \\
\hline Banheiro & 0.2081 & 0.0199 & 0.1691 & 0.2081 & 0.2471 & 0.2081 \\
\hline Elevador & -0.0073 & 0.0050 & -0.0172 & -0.0073 & 0.0026 & -0.0073 \\
\hline Unid. Andar & 0.0169 & 0.0037 & 0.0097 & 0.0169 & 0.0241 & 0.0169 \\
\hline Empreend. Horizontal & 0.1031 & 22.3577 & -43.7927 & 0.1025 & 43.9623 & 0.1031 \\
\hline Empreend. Vertical & -0.0941 & 22.3577 & -43.9899 & -0.0947 & 43.7651 & -0.0941 \\
\hline Iluminação & -0.0511 & 0.0178 & -0.0860 & -0.0511 & -0.0162 & -0.0511 \\
\hline Renda & 0.0011 & 0.0351 & -0.0057 & 0.0011 & 0.0080 & 0.0011 \\
\hline Dist. Metrô & -0.0833 & 0.0246 & -0.1316 & -0.0833 & -0.0351 & -0.0833 \\
\hline Dist. CPTM & -0.0959 & 0.0314 & -0.1575 & -0.0959 & -0.0344 & -0.0959 \\
\hline Dist. Favela & -0.0028 & 0.0248 & -0.0516 & -0.0028 & 0.0459 & -0.0028 \\
\hline Dist. Escola & -0.0055 & 0.0499 & -0.1035 & -0.0055 & 0.0924 & -0.0055 \\
\hline Dist. Ubs & 0.0672 & 0.0355 & -0.0024 & 0.0672 & 0.1368 & 0.0672 \\
\hline Crime & 0.0100 & 0.0011 & 0.0079 & 0.0100 & 0.0121 & 0.0100 \\
\hline Colormap & -0.1782 & 0.0722 & -0.3200 & -0.1782 & -0.0365 & -0.1782 \\
\hline Dist. Rep. Guarapiranga & 0.0159 & 0.0630 & -0.1078 & 0.0159 & 0.1396 & 0.0159 \\
\hline Dist. Rep. Billings & -0.0205 & 0.0580 & -0.1344 & -0.0205 & 0.0933 & -0.0205 \\
\hline Precisão Gaussiana & 2.2068 & 0.0370 & 2.1355 & 2.2064 & 2.2805 & 2.2054 \\
\hline Precisão Tendência & 173.4976 & 49.8030 & 90.3783 & 169.1876 & 283.4492 & 160.3247 \\
\hline Precisão Ciclo & 89.1210 & 25.1568 & 47.8787 & 86.5966 & 145.6272 & 81.6643 \\
\hline PACF1 & -0.3145 & 0.1853 & -0.6394 & -0.3268 & 0.0779 & -0.3551 \\
\hline PACF2 & -0.0403 & 0.1466 & -0.3513 & -0.0280 & 0.2141 & 0.0202 \\
\hline $\log \tau$ & -5.2447 & 0.0879 & -5.4128 & -5.2465 & -5.0679 & -5.2522 \\
\hline $\log \kappa$ & 4.2597 & 0.1128 & 4.0302 & 4.2632 & 4.4727 & 4.2738 \\
\hline Marginal Lik & -8550.89 & & & & & \\
\hline DIC & 16204.97 & & & & & \\
\hline WAIC & 16156.21 & & & & & \\
\hline
\end{tabular}

${ }^{1} \overline{\text { Nota: Valores das variável dependente e das covariadas renda medidas em milhares de Reais }}$

Tabela 6.3.

O modelo selecionado pelos critérios de informação está apresentado na Tabela 6.4. Podemos observar que esse modelo é menos parcimonioso que o modelo selecionado pela presença do zero no intervalo de credibilidade, contendo o tipo de empreeendimento e o número de elevadores como variáveis adicionais.

Nos dois modelos os parâmetros comuns estimados tiveram sinais e magnitudes similares. Primeiro, em relação às características intrínsecas dos imóveis: $\mathrm{O}$ parâmetro associado ao número de dormitórios foi estimado com uma média posterior negativa, o que significa que com mais dormitórios, menor será o valor por metro quadrado. Já para o parâmetro associado ao número de garagens, temos o a média posterior positiva, significando que um aumento no número de vagas de garagem gera um aumento no valor do preço por metro quadrado. Um aspecto importante é que nessa especificação a renda per capita é excluída, o que pode ser explicado pela presença da variável de Iluminação 
Tabela 6.3 - Resultados - Estimação do modelo Final - Critério significância

\begin{tabular}{ccccccc}
\hline & média & $\mathrm{dp}$ & $.025 \mathrm{q}$ & $.5 \mathrm{q}$ & $.975 \mathrm{q}$ & moda \\
\hline Dormitório & -0.1624 & 0.0165 & -0.1947 & -0.1624 & -0.1301 & -0.1624 \\
Garagem & 0.2111 & 0.0125 & 0.1867 & 0.2111 & 0.2356 & 0.2111 \\
Banheiro & 0.2030 & 0.0198 & 0.1642 & 0.2030 & 0.2418 & 0.2030 \\
Dist. Metrô & -0.0801 & 0.0177 & -0.1149 & -0.0801 & -0.0453 & -0.0801 \\
Dist. CPTM & -0.1014 & 0.0307 & -0.1617 & -0.1015 & -0.0412 & -0.1014 \\
Dist .Ubs & 0.0682 & 0.0346 & 0.0002 & 0.0682 & 0.1361 & 0.0682 \\
Crime & 0.0097 & 0.0011 & 0.0076 & 0.0097 & 0.0118 & 0.0097 \\
Iluminação & -0.0516 & 0.0177 & -0.0863 & -0.0516 & -0.0169 & -0.0516 \\
Colormap & -0.1385 & 0.0717 & -0.2793 & -0.1385 & 0.0021 & -0.1385 \\
Precisão Gaussiana & 2.1926 & 0.0367 & 2.1220 & 2.1920 & 2.2661 & 2.1904 \\
Precisão Tendência & 183.8457 & 51.2950 & 105.1278 & 176.3916 & 304.6922 & 162.3897 \\
Precisão Ciclo & 79.3564 & 19.6251 & 45.7780 & 77.8926 & 122.1853 & 75.1606 \\
PACF1 & -0.1478 & 0.1278 & -0.3756 & -0.1565 & 0.1224 & -0.1846 \\
PACF2 & 0.0901 & 0.1277 & -0.1523 & 0.0869 & 0.3452 & 0.0724 \\
log $\tau$ & -5.2778 & 0.0889 & -5.4585 & -5.2752 & -5.1091 & -5.2660 \\
log $\kappa$ & 4.3159 & 0.1105 & 4.1069 & 4.3125 & 4.5409 & 4.3001 \\
Marginal Lik & -8490.34 & & & & & \\
DIC & 16249.74 & & & & & \\
WAIC & 16199.39 & & & & & \\
\hline
\end{tabular}

${ }^{1}$ Nota: Valores das variável dependente e das covariadas renda medidas em milhares de Reais

no modelo. A variável de iluminação apresenta um valor negativo em relação a variável dependente, o que não esperávamos, pois entende-se que a variável radiação seja uma proxy de infraestrutura e renda. Há uma dificuldade em implementar esta variável, pois a região da cidade de São Paulo é bem saturada, como pode ser visto na Figura 5.2b e na Tabela 5.1, mas também pode ser interpretada como um efeito de saturação de mercado, ou seja, lançamentos em áreas já densamente habitadas podem ter uma menor demanda, ou então serem lançamentos de empreendimentos para famílias de menor renda per capita. Acreditamos que conforme um lançamento imobiliário tenha uma proximidade maior com os serviços básicos e essenciais, maior será o valor do preço por metro quadrado. As variáveis relacionadas a distância as estações de trem da CPTM como ao metrô apresentaram uma relação negativa com a variável dependente, a média posterior ficou em valores próximos a -0.09 para essas duas variáveis nos dois modelos, sendo um valor esperado, podemos inferir que quanto mais próximos os lançamentos imobiliários são das estações, mais valorizados eles são. Em relação aos hiperparâmetros associados aos componentes latentes do modelo, podemos observar que a precisão do erro não espacial, "Precisão Gaussiana", foi estimada com uma média posterior próxima ao valor de 2.20 nos dois modelos, o que representa uma variância posterior próxima a 0.45 , o que colocado na escala de preços representa um componente bastante relevante no preço, indicando que há um elemento importante nos preços que não é explicado por efeitos hedônicos, amenidades, tendências temporais e componentes espaciais.

A interpretação dos componentes de tendência e ciclo é relacionada a parametri- 
Tabela 6.4 - Resultados - Estimação do modelo Final DIC

\begin{tabular}{ccccccc}
\hline & média & $\mathrm{dp}$ & $.025 \mathrm{q}$ & $.5 \mathrm{q}$ & $.975 \mathrm{q}$ & moda \\
\hline Dormitório & -0.1408 & 0.0167 & -0.1736 & -0.1408 & -0.1079 & -0.1408 \\
Garagem & 0.2068 & 0.0126 & 0.1820 & 0.2068 & 0.2316 & 0.2068 \\
Banheiro & 0.2093 & 0.0198 & 0.1704 & 0.2093 & 0.2481 & 0.2093 \\
Elev & -0.0069 & 0.0050 & -0.0168 & -0.0069 & 0.0029 & -0.0069 \\
Uniandar & 0.0169 & 0.0037 & 0.0097 & 0.0169 & 0.0241 & 0.0169 \\
Empreend. Horizontal & 0.1020 & 22.3514 & -43.7814 & 0.1014 & 43.9488 & 0.1020 \\
Empreend. Vertical & -0.0965 & 22.3514 & -43.9799 & -0.0971 & 43.7503 & -0.0965 \\
Dist. Metrô & -0.0812 & 0.0180 & -0.1166 & -0.0812 & -0.0459 & -0.0812 \\
Dist. CPTM & -0.0988 & 0.0309 & -0.1595 & -0.0988 & -0.0381 & -0.0988 \\
Dist .Ubs & 0.0628 & 0.0345 & -0.0050 & 0.0628 & 0.1306 & 0.0628 \\
Crime & 0.0099 & 0.0011 & 0.0078 & 0.0099 & 0.0120 & 0.0099 \\
Iluminação & -0.0491 & 0.0177 & -0.0838 & -0.0491 & -0.0145 & -0.0491 \\
Colormap & -0.1637 & 0.0716 & -0.3042 & -0.1637 & -0.0234 & -0.1637 \\
Precisão Gaussiana & 2.2075 & 0.0370 & 2.1365 & 2.2069 & 2.2816 & 2.2053 \\
Precisão Tendência & 183.7147 & 52.6269 & 104.0099 & 175.6948 & 308.6281 & 160.7317 \\
Precisão Ciclo & 79.0403 & 19.6767 & 45.7888 & 77.3835 & 122.4925 & 74.2645 \\
PACF1 & -0.1318 & 0.1365 & -0.3761 & -0.1407 & 0.1559 & -0.1699 \\
PACF2 & 0.0993 & 0.1323 & -0.1548 & 0.0973 & 0.3611 & 0.0866 \\
log $\tau$ & -5.2670 & 0.0877 & -5.4447 & -5.2646 & -5.1001 & -5.2562 \\
log $\kappa$ & 4.2986 & 0.1103 & 4.0897 & 4.2954 & 4.5221 & 4.2840 \\
Marginal Lik & -8489.01 & & & & & \\
DIC & 16200.73 & & & & & \\
WAIC & 16150.51 & & & & & \\
\hline
\end{tabular}

${ }^{1}$ Nota: Valores das variável dependente e das covariadas renda medidas em milhares de Reais

zação utilizada. O componente de tendência é obtido como um processo de nível local, correspondente a um fator latente gerado por um passeio aleatório. Para verificarmos a existência de ciclos, fizemos uma estimativa de um ciclo de preço espacial através da dinâmica autorregressiva de segunda ordem $c_{t}=\phi_{1} c_{t-1}+\phi_{2} c_{t-2}+\eta_{c}$. Para verificar a ocorrência de ciclos, checa-se no modelo autorregressivo de segunda ordem a ocorrência de raízes complexas. Para isso, verifica-se a desigualdade da inequação $\phi_{1}^{2}+4 \phi_{2}<0$. Para isso, estima-se os parâmetros de autocorrelação de primeira e segunda ordem (PACF1 e PACF2 nas tabelas de resultados). Para o modelo com o conjunto completo de variáveis encontramos coeficientes autoregressivos de -0.3271 e -0.0403 , que correspondem a uma raíz negativa e um ciclo com período de 2.49 períodos. Nos modelos restritos as raízes são reais, e assim não há formação de ciclos, sendo que nesse caso o $\operatorname{AR}(2)$ tem a interpretação usual de dependência de segunda ordem.

As Figuras 6.2 e 6.3 apresentam os resultados da estimação dos componentes de tendência e ciclo $(\mathrm{AR}(2))$ para o modelo completo e o modelo restrito selecionado pelo critério DIC. Verifica-se que há um fator de tendência positivo para o preço do metro quadrado dos lançamentos, acompanhando a valorização dos preços, e também que o componente $\mathrm{AR}(2)$ apresenta uma variabilidade importante no padrão de preços. 
Figura 6.2 - Gráfico de tendência e ciclo - modelo completo
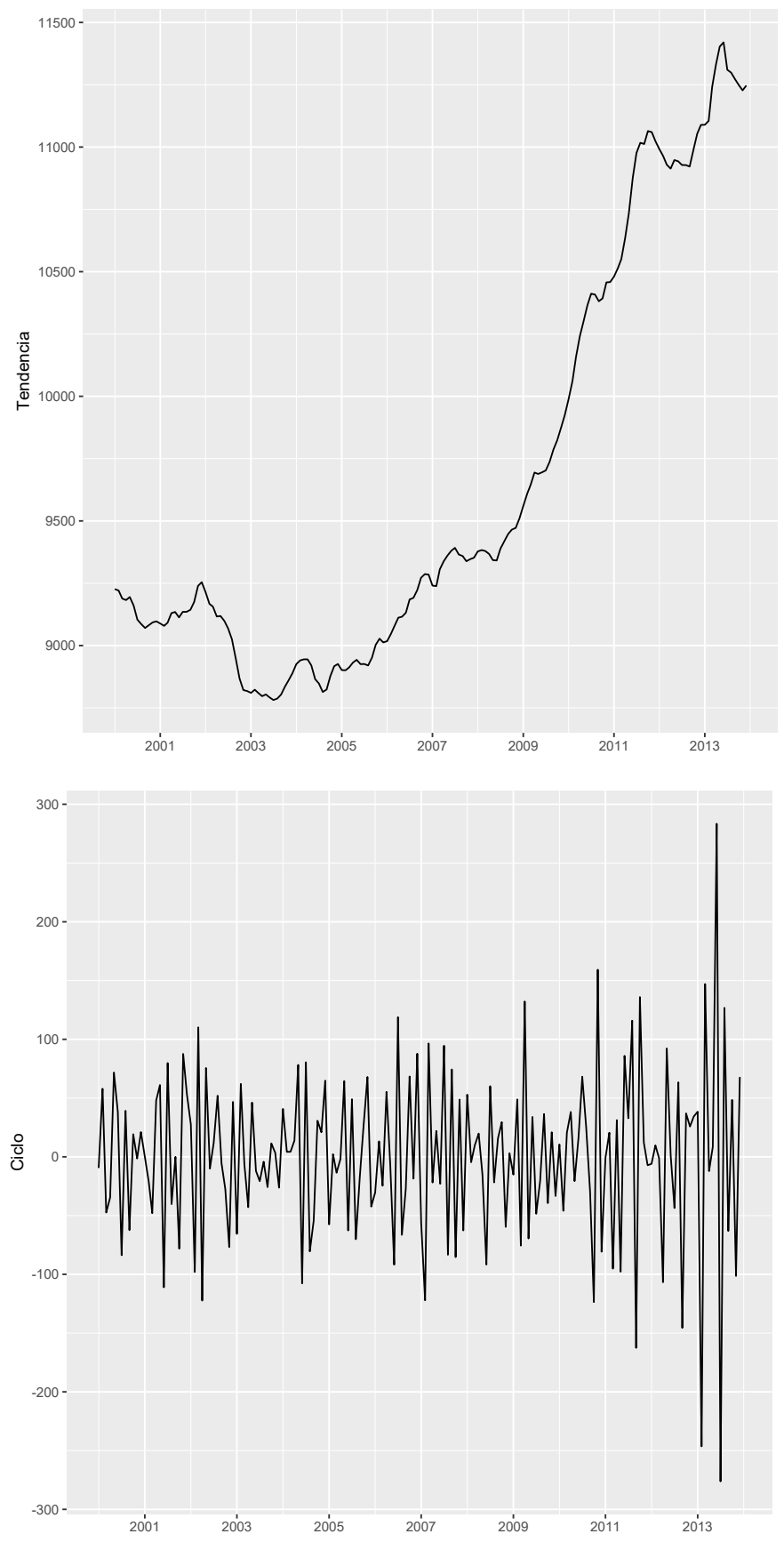

Já os parâmetros $\log \tau$ e $\log \kappa$ são utilizados para ver a dependência espacial. Estes parâmetros foram utilizados para calcular a função de correlação espacial correspondente a matriz de covariância Matérn com os parâmetros avaliados na média posterior. Como estes parâmetros tem interpretação mais complexa, a forma mais fácil de visualizar estes resultados é através do efeito aleatório espacial estimado pelo modelo. Para isto, apresentamos nas Figuras 6.4 e 6.5 os efeitos aleatórios estimados para o modelo completo e o modelo selecionado pelo critério DIC.

Podemos observar nestas figuras que o efeito aleatório espacial captura de forma 
Figura 6.3 - Gráfico de tendência e ciclo - modelo restrito pelo DIC
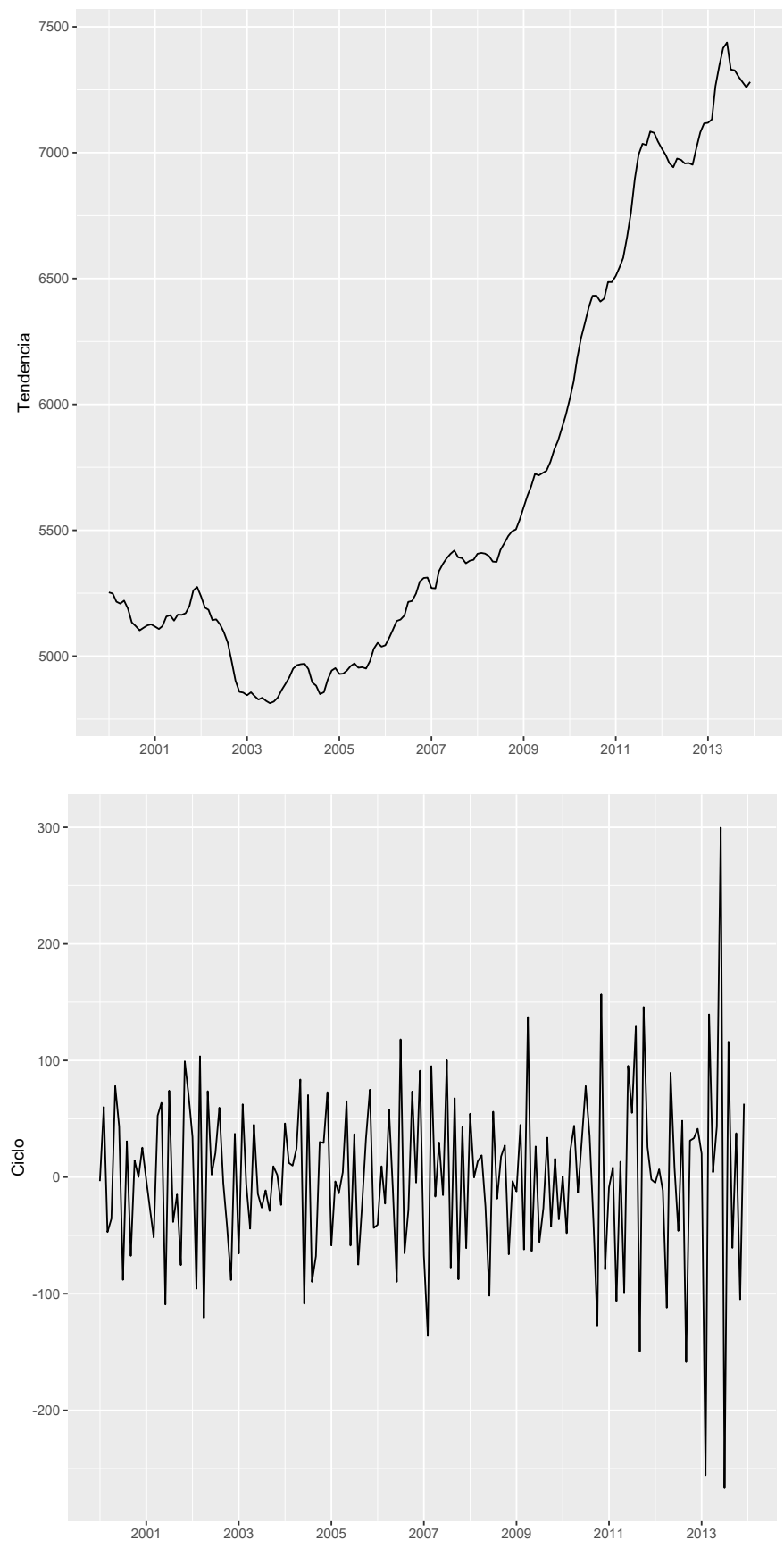

muito similar, nos dois modelos, uma tendência de valorização nas regiões centrais da cidade. Note que este componente pode ser explicado como uma agregação de todas as variáveis não incluídas no modelo com dependência espacial, o que no caso indica o componente sistemático nos preços de lançamento que não pode ser explicado pelo conjunto de variáveis explicativas e pelos componentes dinâmicos. Esse resultado indica que existe um componente espacial bastante relevante nos preços de imóveis, dando suporte ao uso de modelos com controle para efeitos de locação.

Para mostrar a importância dos componentes latentes na análise dos preços de 
Figura 6.4 - Efeito Aleatório - SPDE-Matérn - modelo Completo

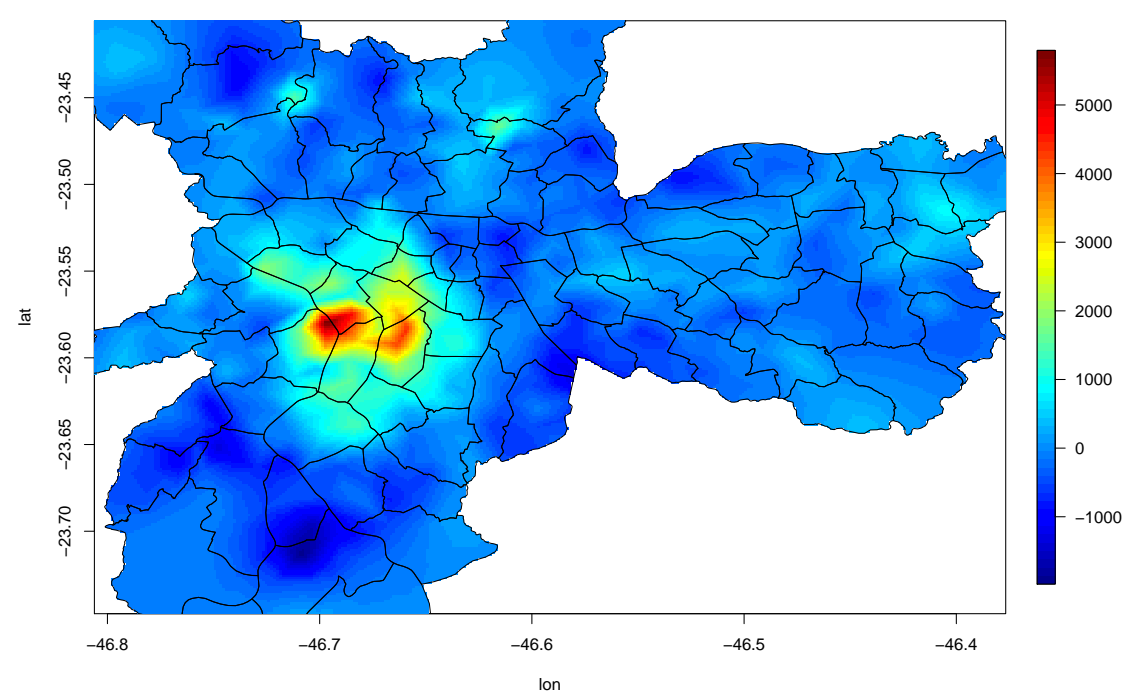

Figura 6.5 - Efeito Aleatório - SPDE-Matérn - modelo Restrito

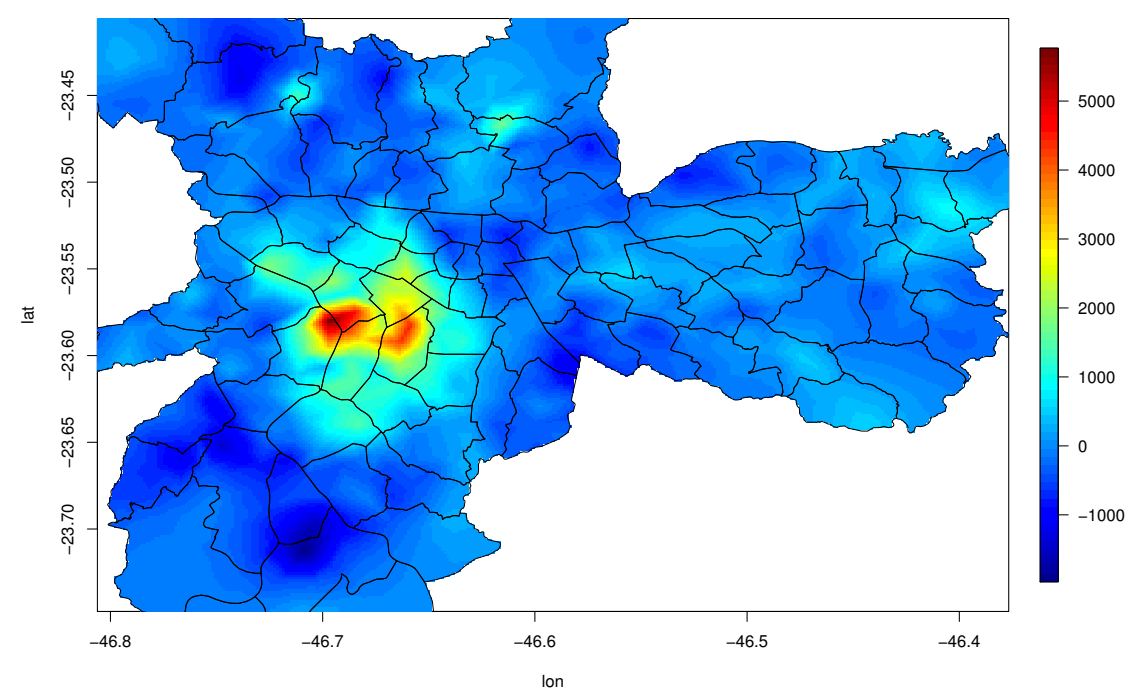

lançamentos, mostramos na Figura 6.6 o ajuste do modelo dado pela soma dos componentes de tendência, ciclo e espaciais para o modelo restrito selecionado pelo critério DIC, para o último período da amostra. Podemos observar que este modelo reproduz de forma adequada o nível e a heterogeneidade espacial nos preços de lançamento na cidade de São Paulo, indicando a utilidade dos modelos propostos neste trabalho. 
Figura 6.6 - modelo Ajustado - modelo restrito selecionado pelo critério DIC

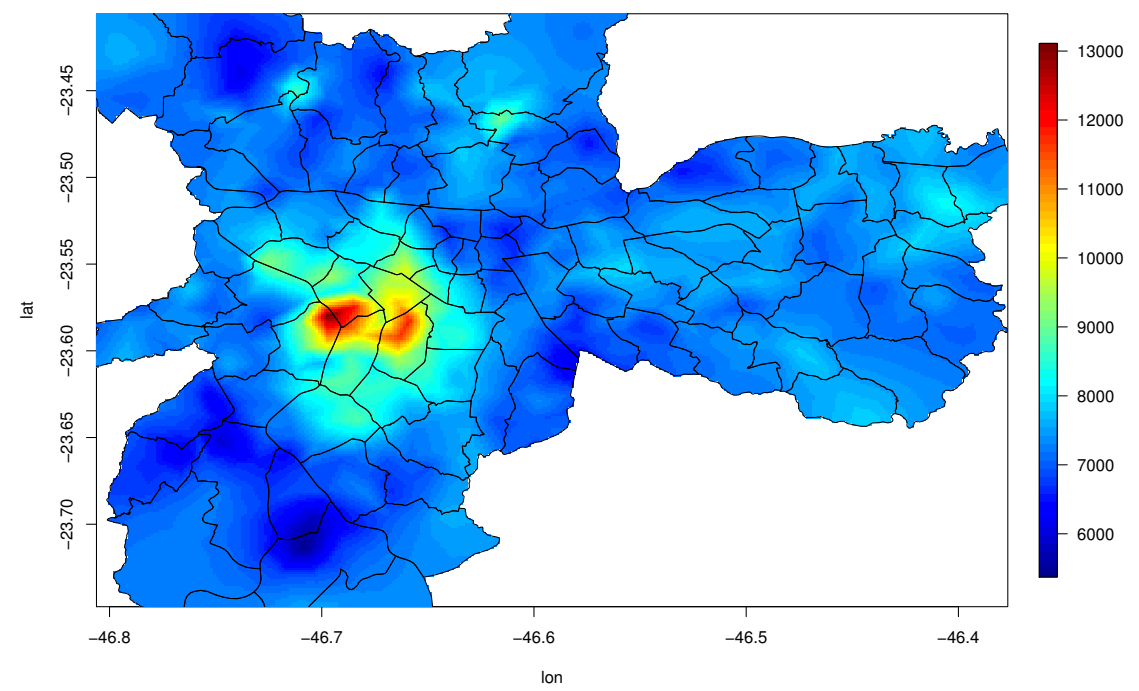

\subsection{Comparação com o modelo ICAR}

Uma abordagem alternativa foi apresentada ao final da Seção de Metodologia na Seção 4.2, em que se obtém uma parametrização similar a de um modelo ICAR como um caso especial do modelo SPDE-Matérn assumindo $\alpha=1$ no $R^{2}$. Para verificar os resultados empíricos desta especificação, estimamos esta parametrização para o conjunto de variáveis selecionadas pelo critério DIC. Os resultados da estimação do modelo ICAR estão apresentados na Tabela 6.5, em que são apresentadas as estimativas Bayesianas $a$ posteriori e os respectivos intervalos de credibilidade para as características estudadas.

De forma geral, a parametrização ICAR apresenta valores de parâmetros bastante similares ao caso do modelo SPDE-Matérn com $\alpha=2$, mas os resultados do DIC apontam uma leve melhora em relação a parametrização usual. Como os valores são bem próximos, é difícil apontar uma vantagem significativa no uso desta parametrização, mas é importante mostrar que esta especificação apresenta resultados consistentes, e é uma forma de realizar uma comparação com a classe usual de modelos baseados na parametrização CAR que é dominante na modelagem estatística de modelos espaciais. As Figuras 6.7 e 6.8 apresentam os componentes dinâmicos e espaciais estimados nesta parametrização, que novamente são bastante similares a especificação padrão do modelo SPDE-Matérn.

\subsection{Modelo com estrutura dinâmica para os efeitos aleatórios espaciais}

Uma possível limitação dos modelos estudados até agora está em assumir que os efeitos espacias são constantes no tempo. Especialmente para o mercado imobiliário é esperado que o padrão espacial de preços se modifique no tempo, indicando mudanças nos 
Tabela 6.5 - Resultados - Estimação do modelo ICAR

\begin{tabular}{ccccccc}
\hline & média & $\mathrm{dp}$ & $.025 \mathrm{q}$ & $.5 \mathrm{q}$ & $.975 \mathrm{q}$ & moda \\
\hline Dormitório & -0.1408 & 0.0167 & -0.1737 & -0.1408 & -0.1080 & -0.1408 \\
Garagem & 0.2063 & 0.0126 & 0.1815 & 0.2063 & 0.2311 & 0.2063 \\
Banheiro & 0.2091 & 0.0198 & 0.1703 & 0.2091 & 0.2480 & 0.2091 \\
Elevador & -0.0067 & 0.0050 & -0.0165 & -0.0067 & 0.0032 & -0.0067 \\
Uniandar & 0.0169 & 0.0037 & 0.0097 & 0.0169 & 0.0241 & 0.0169 \\
Empreend. Horizontal & 0.0315 & 22.6790 & -44.4950 & 0.0309 & 44.5209 & 0.0315 \\
Empreend. Vertical & -0.1692 & 22.6790 & -44.6957 & -0.1699 & 44.3201 & -0.1692 \\
Dist. Metrô & -0.0672 & 0.0222 & -0.1109 & -0.0672 & -0.0236 & -0.0672 \\
Dist. CPTM & -0.0779 & 0.0303 & -0.1373 & -0.0779 & -0.0186 & -0.0779 \\
Dist. Ubs & 0.0662 & 0.0347 & -0.0020 & 0.0662 & 0.1343 & 0.0662 \\
Crime & 0.0099 & 0.0011 & 0.0078 & 0.0099 & 0.0120 & 0.0099 \\
Iluminação & -0.0491 & 0.0175 & -0.0835 & -0.0491 & -0.0147 & -0.0491 \\
Colormap & -0.1587 & 0.0714 & -0.2988 & -0.1587 & -0.0187 & -0.1587 \\
Precisão Gaussiana & 2.2111 & 0.0369 & 2.1389 & 2.2109 & 2.2842 & 2.2109 \\
Precisão Tendência & 150.3496 & 28.3411 & 99.9312 & 148.8339 & 210.6240 & 146.4532 \\
Precisão Ciclo & 79.5239 & 16.5764 & 52.5328 & 77.5979 & 117.2482 & 73.7757 \\
PACF1 & -0.0448 & 0.1064 & -0.2406 & -0.0500 & 0.1751 & -0.0684 \\
PACF2 & 0.1498 & 0.1141 & -0.0555 & 0.1428 & 0.3867 & 0.1120 \\
log $\tau$ & -0.0518 & 0.0491 & -0.1458 & -0.0529 & 0.0470 & -0.0567 \\
log $\kappa$ & 2.6124 & 0.2122 & 2.2363 & 2.5965 & 3.0645 & 2.5376 \\
Marginal Lik & -8481.88 & & & & & \\
DIC & 16198.52 & & & & & \\
WAIC & 16147.89 & & & & & \\
\hline
\end{tabular}

${ }^{1}$ Nota: Valores das variável dependente e das covariadas renda medidas em milhares de Reais

padrões de urbanização, população e demanda na cidade, especialmente em um período longo de tempo. Embora é esperado que parte destes efeitos seja capturado pelas variáveis explicativas incluídas, é possível que haja padrões não capturados, que levariam a mudanças no padrão dos efeitos espaciais.

Para tratar desta possibilidade, na última classe de especificações, nós tornamos os efeitos aleatórios espaciais variantes no tempo. Essa especificação permite capturar mudanças no padrão espacial de inovações, indicando como o mercado de imóveis evolui espacialmente no tempo. Para realizar esta análise nós utilizamos uma especificação alternativa dada pela seguinte estrutura para os efeitos aleatórios espaciais:

$$
\xi_{t}=\rho \xi_{t-1}+\omega_{t}
$$

Nesta formulação a principal modificação é a introdução de um coeficiente $\rho$ ligando o campo aleatório espacial no período $t$ ao período $t-1$, em uma estrutura análoga a um processo autoregressivo, mas agora para todo o efeito espacial no contínuo. Esta estrutura permite capturar o grau de dependência em relação ao passado, capturando de forma flexível as mudanças no padrão espacial. Uma possível formulação alternativa seria tratar o efeito aleatório espacial como um processo de passeio aleatório, mas esta 
Figura 6.7 - Gráfico de Tendência e Ciclo - ICAR
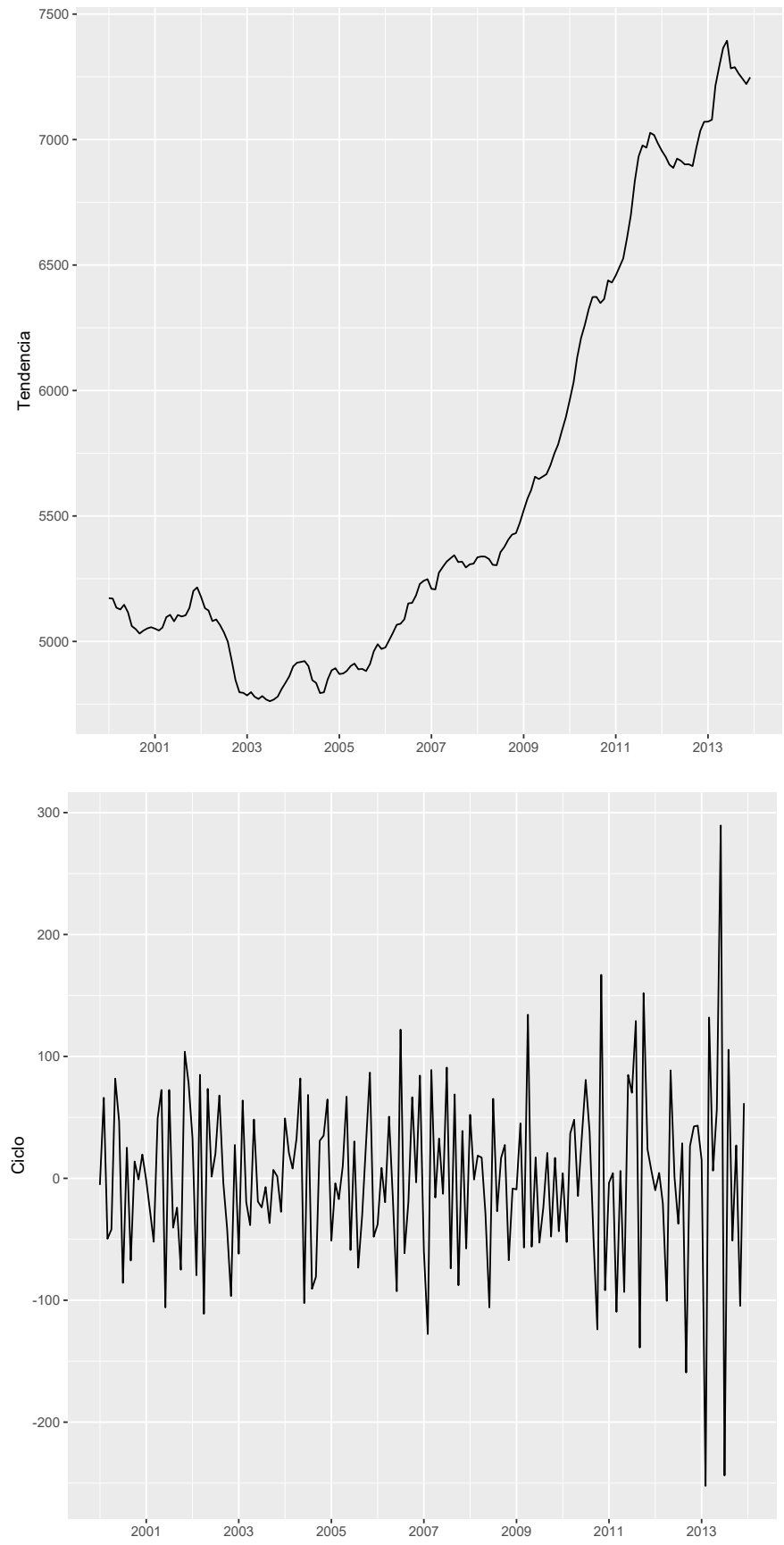

especificação leva a problemas de identificação com o componente de tendência no modelo. Note que a especificação autoregressiva permite capturar este efeito se o parâmetro $\rho$ é muito próximo de um. Note que também não incluímos o componente de ciclo, devido a problemas possíveis de identificação nesta especificação.

A especificação de um modelo com o componente espacial variante no tempo representa um problema computacional bastante maior que o modelo com efeitos aleatórios espaciais fixos, já que esta parametrização implica em uma estrutura de representação muito mais complexa, como discutido em Blangiardo e Cameletti (2015), por exemplo. 


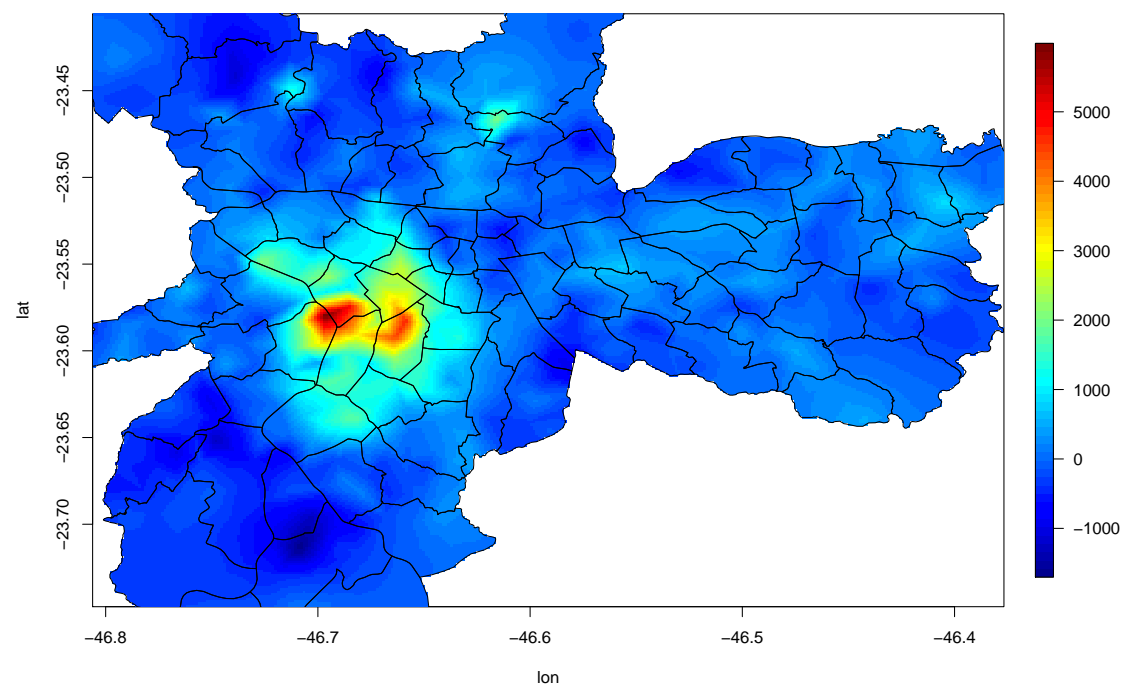

Esta parametrização é especialmente custosa em termos de memória necessária para a representação computacional do modelo. Devido a estas limitações computacionais, nós estimamos duas formas do modelo com efeitos aleatórios espaciais variantes no tempo.

A primeira parametrização assume que os efeitos aleatórios espacias mudam a cada ano, e não a cada mês. Assim o efeito é constante em cada ano da amostra, mas varia entre anos. Note que o modelo continua a ser estimado com dados mensais, apenas é colocada uma restrição no padrão de variação dos efeitos aleatórios. Os resultados desta especificação estão apresentados na Tabela 6.6.

Podemos observar que o uso da parametrização com efeitos aleatórios variantes no tempo representa um ganho substancial de ajuste para o modelo. A verossimilhança marginal desta especificação apresenta o valor -7846.52, um grande ganho em relação ao valor de -8489.01 apresentado pelo modelo equivalente com efeitos espaciais fixos no tempo. Os critérios de informação DIC e WAIC também indicam um ganho substancial de ajuste nesta especificação. Podemos observar que o coeficiente $\rho$ estimado tem média posterior de 0.938 , indicando uma elevada persistência para o padrão espacial, mas com intervalo de credibilidade contendo valores abaixo da unidade, indicando um padrão estacionário para os efeitos aleatórios espaciais. De forma geral, os coeficientes para as covariadas são similares aos obtidos com os demais modelos, bem como para a componente de tendência obtida (Figura 6.9).

As figuras 6.10-6.13 mostram os efeitos espaciais estimados ano a ano para esta especificação do modelo. Em geral podemos notar que o padrão espacial é similar em todos os anos, indicando um padrão de persistência na heterogeneidade espacial. O principal efeito na especificação dinâmica é capturar mudanças da escala dos efeitos espaciais. Para 
Tabela 6.6 - Modelo com estrutura dinâmica para os efeitos aleatórios espaciais - efeitos anuais

\begin{tabular}{ccccccc}
\hline & média & $\mathrm{dp}$ & $.025 \mathrm{q}$ & $.5 \mathrm{q}$ & $.975 \mathrm{q}$ & moda \\
\hline Dormitório & -0.1142 & 0.0152 & -0.1440 & -0.1142 & -0.0844 & -0.1142 \\
Garagem & 0.1693 & 0.0115 & 0.1467 & 0.1693 & 0.1918 & 0.1693 \\
Banheiro & 0.2580 & 0.0181 & 0.2224 & 0.2580 & 0.2935 & 0.2580 \\
Elevador & 0.0005 & 0.0047 & -0.0096 & -0.0005 & 0.0087 & -0.0005 \\
Uniandar & 0.0140 & 0.0036 & 0.0070 & 0.0140 & 0.0209 & 0.0140 \\
Empreend. Horizontal & 0.1057 & 22.3445 & -43.7641 & 0.1051 & 43.9390 & 0.1057 \\
Empreend. Vertical & -0.0932 & 22.3445 & -43.9631 & -0.0939 & 43.7400 & -0.0932 \\
Dist. Metrô & -0.0797 & 0.0143 & -0.1077 & -0.0797 & -0.0518 & -0.0797 \\
Dist. CPTM & -0.1116 & 0.0270 & -0.1646 & -0.1116 & -0.0586 & -0.1116 \\
Dist. Ubs & 0.0357 & 0.0335 & -0.0302 & 0.0357 & 0.1015 & 0.0357 \\
Crime & -0.0006 & 0.0015 & -0.0035 & -0.0006 & 0.0023 & -0.0006 \\
Iluminação & -0.0252 & 0.0196 & -0.0636 & -0.0252 & 0.0131 & -0.0252 \\
Colormap & -0.1719 & 0.0681 & -0.3057 & -0.1719 & -0.0383 & -0.1719 \\
Precisão Gaussiana & 2.971 & 0.0571 & 2.8586 & 2.9708 & 3.0832 & 2.9715 \\
Precisão Tendência & 108.543 & 31.0462 & 60.4361 & 104.2556 & 181.3058 & 96.1938 \\
$\rho$ & 0.938 & 0.0085 & 0.9213 & 0.9379 & 0.9544 & 0.9371 \\
log $\tau$ & -5.608 & 0.0821 & -5.7687 & -5.6087 & -5.4462 & -5.6096 \\
log $\kappa$ & 4.553 & 0.0767 & 4.3973 & 4.5547 & 4.6987 & 4.5607 \\
Marginal Lik & -7846.52 & & & & & \\
DIC & 14479.92 & & & & & \\
WAIC & 14396.51 & & & & & \\
\hline
\end{tabular}

${ }^{1}$ Nota: Valores das variável dependente e das covariadas renda medidas em milhares de Reais

Figura 6.9 - Gráfico de Tendência - modelo com efeito dinâmico anual

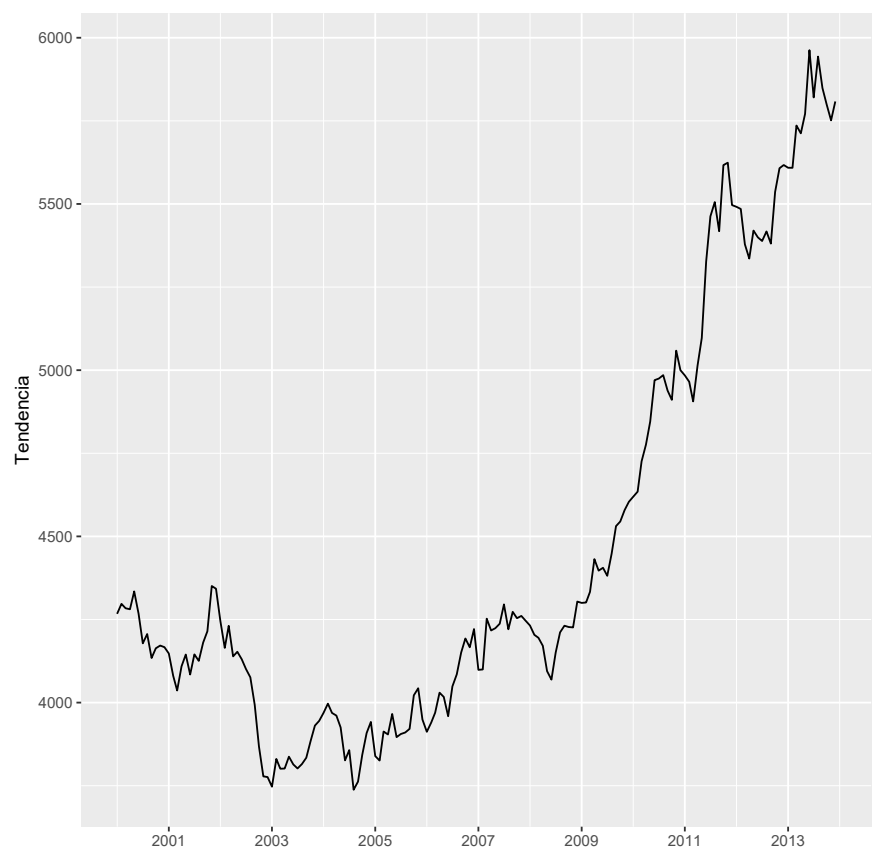

evidenciar este efeito, colocamos na Figura 6.14 a variação entre a média posterior do efeito espacial para os primeiros e últimos anos da amostra. Este efeito mostra um aumento no 
Figura 6.10 - Efeito Aleatório - modelo dinâmico 2000-2003
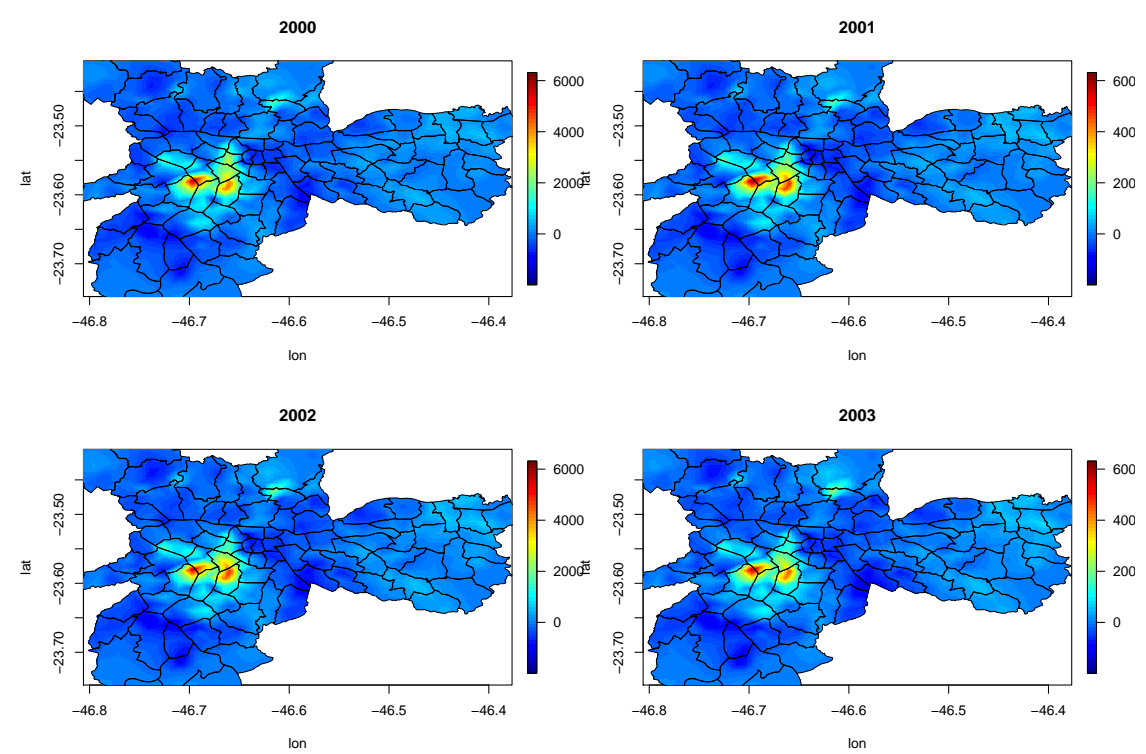

Figura 6.11 - Efeito Aleatório - modelo dinâmico 2004-2007
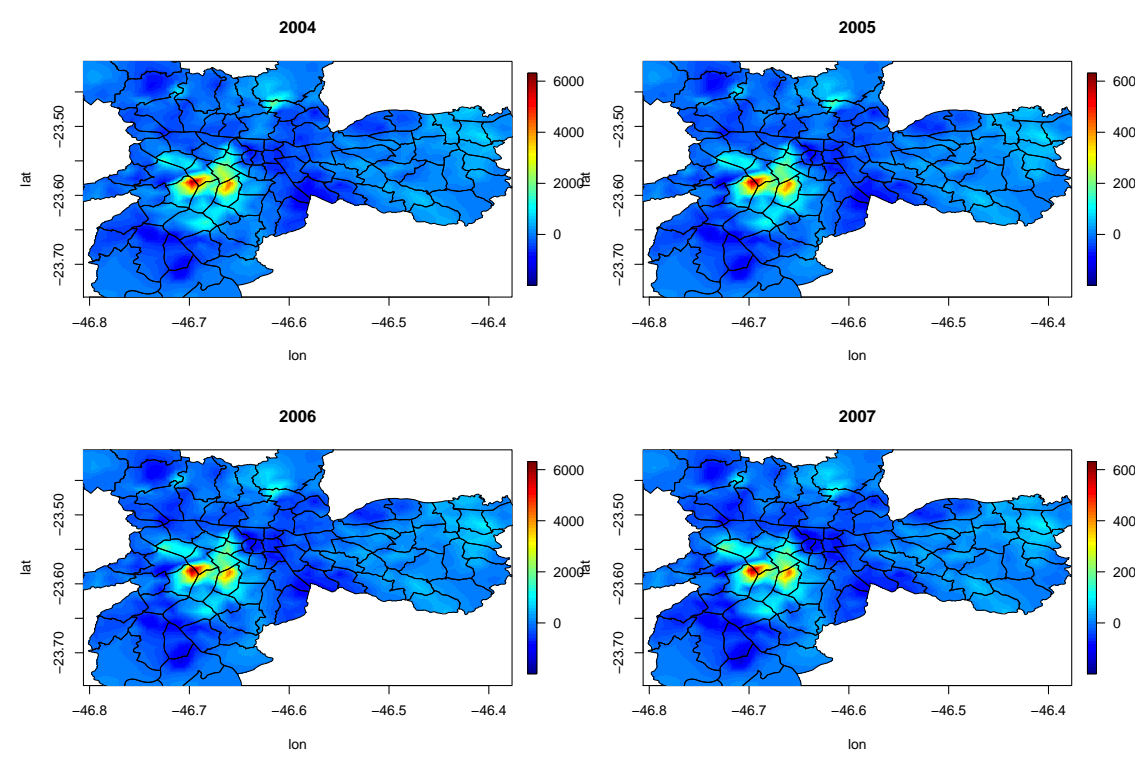

efeito espacial para as regiões centrais e ao sul do centro, indicando um padrão de aumento espacial para as regiões próximas a central que não se observavam no início da amostra, e padrões de desvalorização em algumas regiões específicas. De forma geral, podemos observar que existe um ganho de ajuste e interpretação ao fazer os efeitos espaciais serem variantes no tempo.

A forma mais flexível possível seria colocar os efeitos espaciais variantes a cada período do modelo, correspondente a um efeito mensal espacial. No entanto esta parametrização não pode ser estimada devido ao custo computacional envolvido, levando a erros nos 
Figura 6.12 - Efeito Aleatório - modelo dinâmico 2008-2011
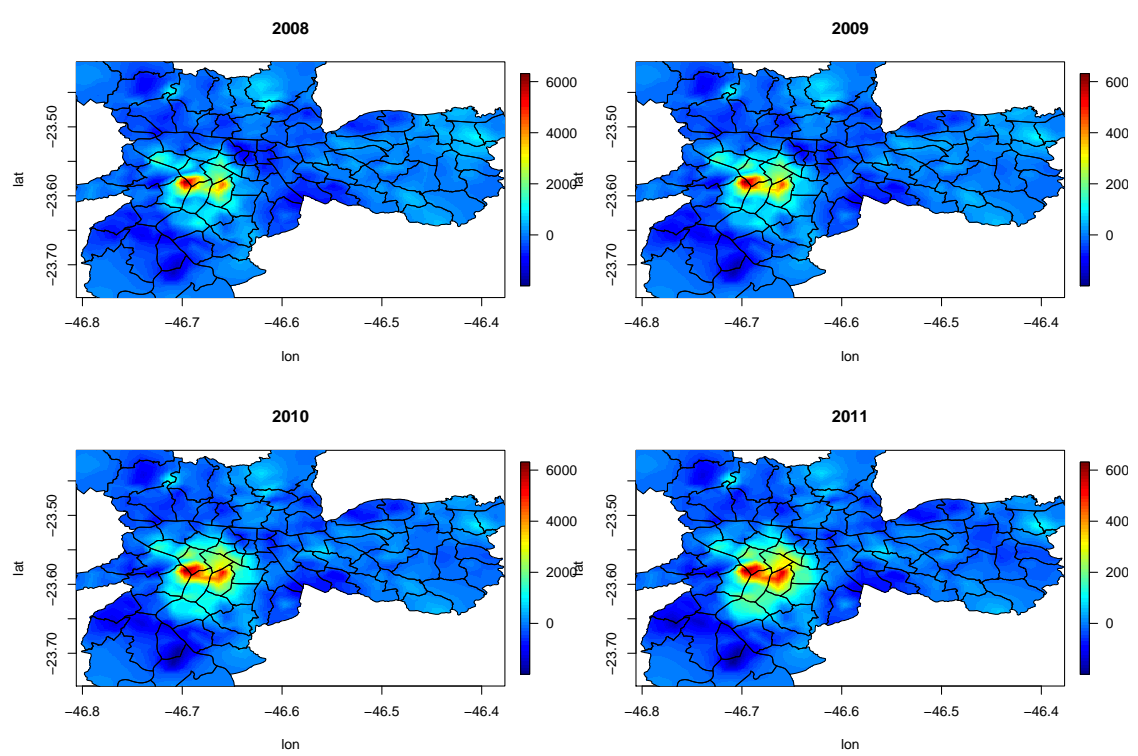

Figura 6.13 - Efeito Aleatório - modelo dinâmico 2012-2013
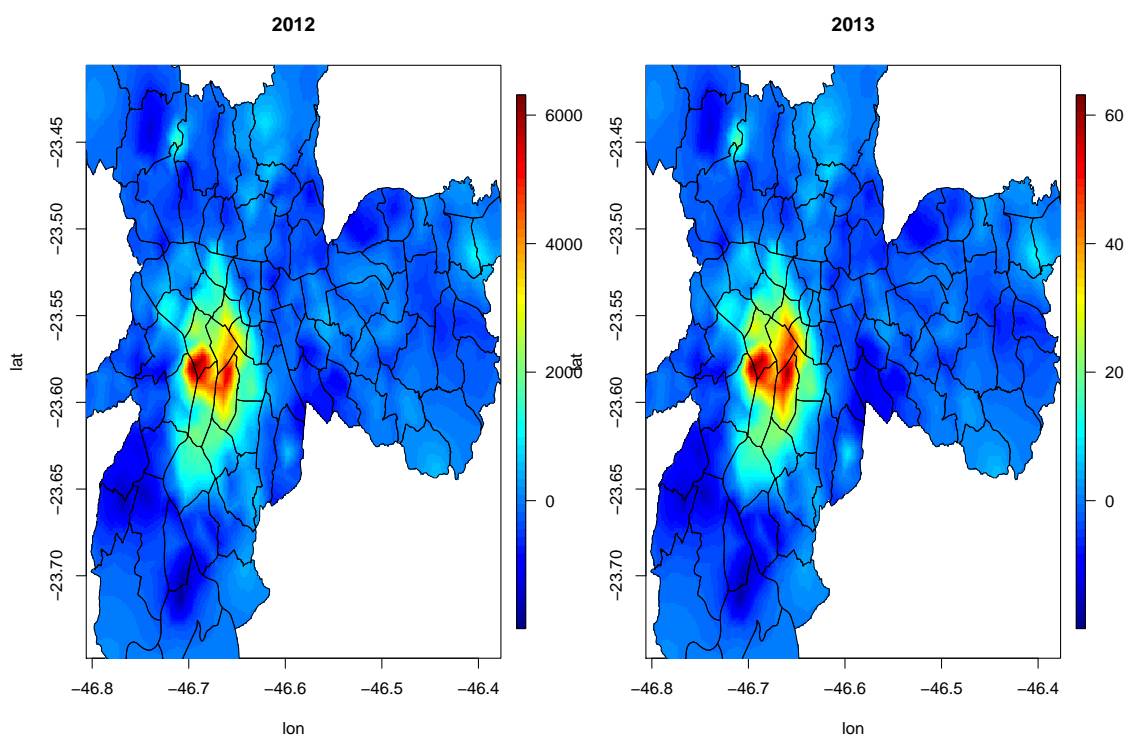

procedimentos relacionados a aproximação da projeção contínua espacial. Para contornar esta restrição nós estimamos o modelo em um mesh mais simples, apresentando na Figura 6.15. Esta escolha de mesh leva a uma aproximação mais pobre para o contínuo espacial, mas ao mesmo tempo possibilita a estimação dos efeitos aleatórios espaciais variantes a cada período do modelo.

A Tabela 6.7 mostra os parâmetros estimados para o modelo com efeitos aleatórios variantes a cada período. Podemos observar que o ajuste do modelo, medido pela verossimilhança marginal e critérios de informação, mostra que esta especificação tem um ajuste 
Figura 6.14 - Efeito Aleatório - modelo dinâmico Variação 2000-2013

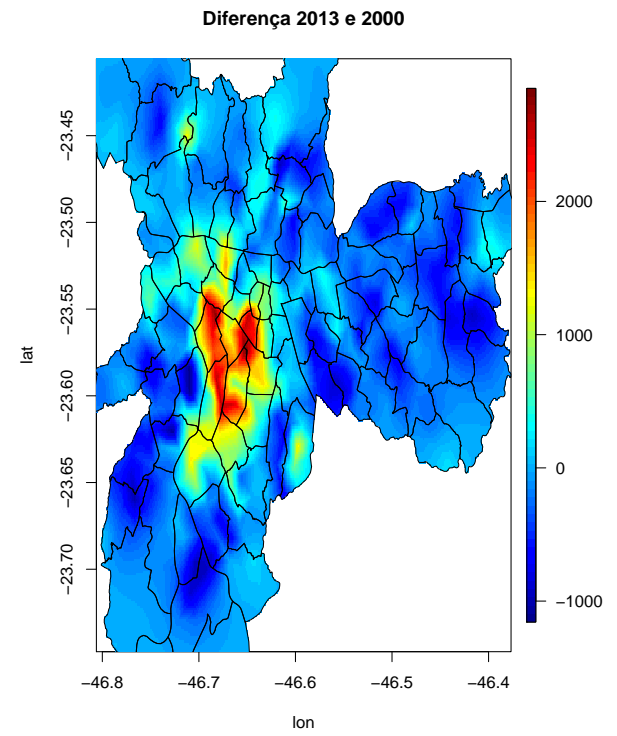

\section{Constrained refined Delaunay triangulation}

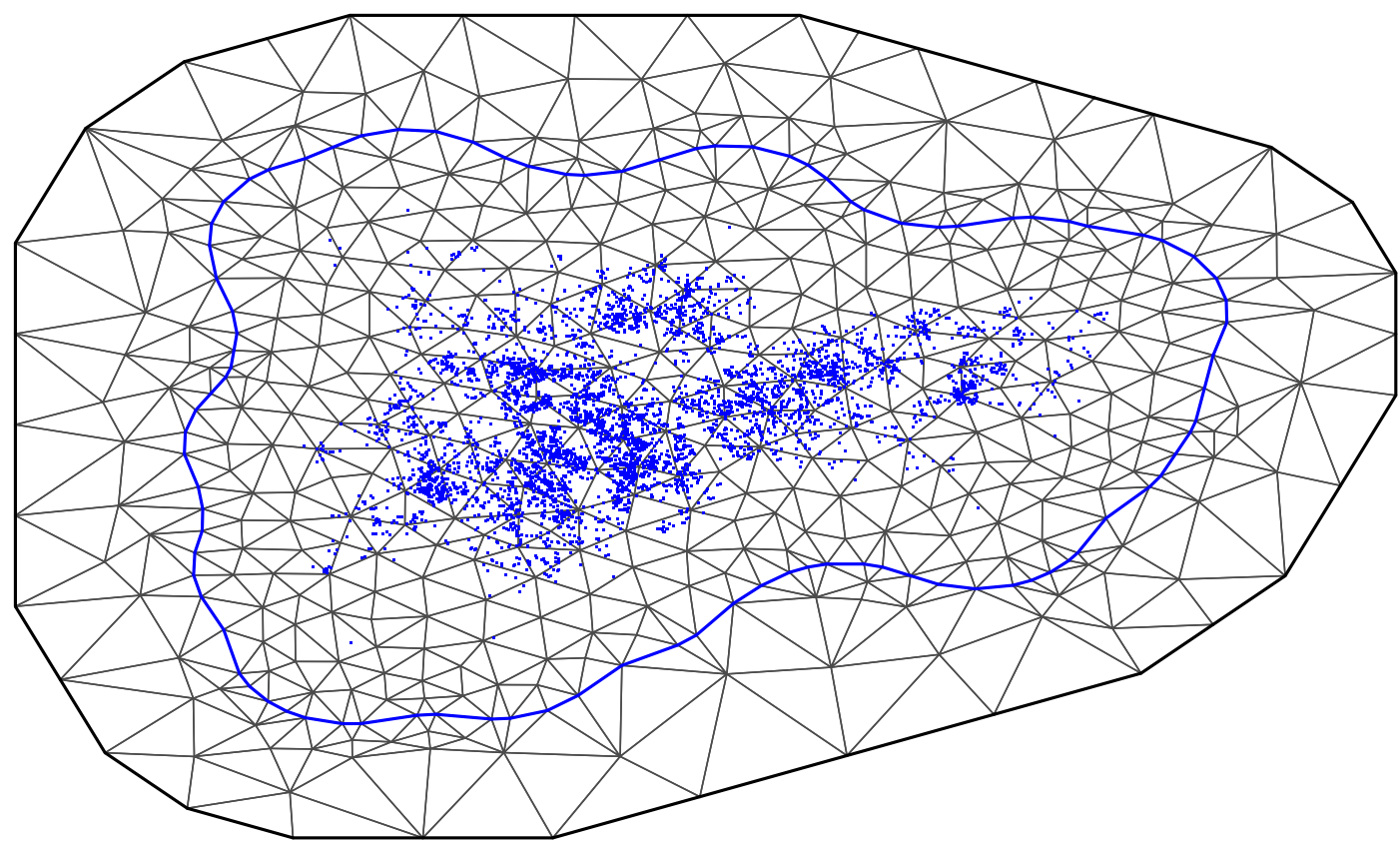

Figura 6.15 - Triangulação Alternativa de Mesh

inferior à obtida pela especificação com efeitos aleatórios espaciais anuais. Note que este efeito é derivado pela piora da aproximação por um mesh mais grosseiro, mas também pode indicar que o padrão de variação anual é suficiente para ajustar o padrão de mudança 
Tabela 6.7 - modelo com estrutura dinâmica para os efeitos aleatórios espaciais - efeitos mensais

\begin{tabular}{ccccccc}
\hline & média & $\mathrm{dp}$ & $.025 \mathrm{q}$ & $.5 \mathrm{q}$ & $.975 \mathrm{q}$ & moda \\
\hline Dormitório & -0.1447 & 0.0162 & -0.1764 & -0.1447 & -0.1130 & -0.1447 \\
Garagem & 0.2425 & 0.0120 & 0.2189 & 0.2425 & 0.2661 & 0.2425 \\
Banheiro & 0.2864 & 0.0193 & 0.2486 & 0.2864 & 0.3242 & 0.2864 \\
Elevador & 0.0013 & 0.0049 & -0.0083 & 0.0013 & 0.0109 & 0.0013 \\
Uniandar & 0.0144 & 0.0036 & 0.0073 & 0.0144 & 0.0215 & 0.0144 \\
Empreend. Horizontal & 0.0954 & 22.3390 & -43.7635 & 0.0948 & 43.9178 & 0.0954 \\
Empreend. Vertical & -0.0864 & 22.3390 & -43.9453 & -0.0870 & 43.7360 & -0.0864 \\
Dist. Metrô & -0.0413 & 0.0145 & -0.0697 & -0.0413 & -0.0129 & -0.0413 \\
Dist. CPTM & -0.1323 & 0.0200 & -0.1716 & -0.1323 & -0.0930 & -0.1323 \\
Dist. Ubs & -0.1400 & 0.0239 & -0.1870 & -0.1400 & -0.0930 & -0.1400 \\
Crime & -0.0019 & 0.0014 & -0.0047 & -0.0019 & 0.0008 & -0.0019 \\
Iluminação & -0.0293 & 0.0205 & -0.0697 & -0.0293 & 0.0110 & -0.0293 \\
Colormap & -0.2002 & 0.0708 & -0.3392 & -0.2002 & -0.0614 & -0.2002 \\
Precisão Gaussiana & 2.5120 & 0.0507 & 2.416 & 2.5107 & 2.6153 & 2.5067 \\
Precisão Tendência & 59.1930 & 32.5860 & 110.816 & 153.6579 & 237.1078 & 141.5765 \\
$\rho$ & 0.9831 & 0.0023 & 0.978 & 0.9833 & 0.9871 & 0.9837 \\
log $\tau$ & -4.8398 & 0.1001 & -5.045 & -4.8358 & -4.6527 & -4.8214 \\
log $\kappa$ & 3.8347 & 0.1006 & 3.645 & 3.8317 & 4.0392 & 3.8207 \\
Marginal Lik & -8283.60 & & & & & \\
DIC & 15612.27 & & & & & \\
WAIC & 15521.58 & & & & &
\end{tabular}

${ }^{1}$ Nota: Valores das variável dependente e das covariadas renda medidas em milhares de Reais

observado no componente espacial, indicando que a complexidade adicional introduzida não representa ganhos substanciais de ajuste no modelo. Como não foi possível estimar o modelo com o mesmo mesh, não podemos quantificar a perda de ajuste dada por esta especificação alternativa.

\subsection{Resultados de ajuste}

Nesta seção apresentamos alguns resultados de ajuste dos modelos estudados neste trabalho. A ideia é verificar o ajuste dentro da amostra para todas as especificações utilizadas, isto é, verificar por algumas métricas as diferenças entre o predito por cada modelo, utilizando a estrutura de covariadas, efeitos dinâmicos e efeitos espaciais, para os lançamentos observados dentro da amostra.

A Tabela 6.8 mostra os resultados de ajuste para diversas especificações de modelos, comparando o erro médio (ME - Mean error), raiz do erro quadrático médio (RMSE - Root Mean squared Error), erro absoluto médio (MAE - Mean absolute error), erro percentual médio (MPE - Mean percentual error) e o erro percentual absoluto médio (MAPE - mean absolute percentual error). Nessa tabela mostramos o ajuste do modelo linear completo (sem efeitos dinâmicos e espaciais), o modelo linear restrito (selecionado pelo DIC), o 
Tabela 6.8 - Resultados de Ajuste

\begin{tabular}{cccccc}
\hline modelo & ME & RMSE & MAE & MPE & MAPE \\
\hline Linear Completo & -0.0074 & 1113.454 & 823.8509 & -4.210556 & 36.8806 \\
Linear Restrito & 0.0002 & 1124.05 & 832.4034 & -14.49283 & 49.98548 \\
Completo & $-4.5642 \mathrm{e}-05$ & 655.3677 & 458.9492 & -1.047128 & 14.93374 \\
Restrito & $-4.5562 \mathrm{e}-05$ & 657.6979 & 460.5405 & -1.013342 & 14.96027 \\
ICAR Restrito & $-4.5978 \mathrm{e}-05$ & 656.9033 & 459.9645 & -1.012166 & 14.94422 \\
Restrito DIC & $-4.5581 \mathrm{e}-05$ & 655.3141 & 458.7789 & -1.043854 & 14.924 \\
ICAR Restrito DIC & $-4.5901 \mathrm{e}-05$ & 654.457 & 458.198 & -1.043449 & 14.90966 \\
Efeitos Espaciais Anuais & $-6.1822 \mathrm{e}-05$ & 542.205 & 368.426 & 0.09103919 & 11.5572 \\
Efeitos Espaciais Mensais & $-6.1390 \mathrm{e}-05$ & 597.1153 & 406.1876 & -0.003450926 & 12.70508 \\
\hline
\end{tabular}

modelo completo (todas as covariadas, mais tendência e ciclo e efeito espacial fixo no tempo), o modelo restrito (correspondente a covariadas selecionadas pela ausência do zero no intervalo de credibilidade, mais tendência e ciclo e efeito espacial fixo no tempo), o modelo ICAR restrito (covariadas selecionadas pela ausência do zero no intervalo de credibilidade, mais tendência e ciclo e efeito espacial fixo no tempo), o modelo restrito DIC (covariadas selecionadas pelo critério DIC, mais tendência e ciclo e efeito espacial fixo no tempo), o modelo ICAR Restrito DIC (modelo ICAR com covariadas selecionadas pelo critério DIC, mais tendência e ciclo e efeito espacial fixo no tempo), e o modelo com Efeitos Espaciais Anuais (corresponde ao modelo com seleção de covariadas pelo DIC, mais tendência e efeitos aleatórios espaciais variantes anualmente) e o modelo com Efeitos Espaciais Mensais (correspondente ao modelo com seleção de covariadas pelo DIC, mais tendência e efeitos aleatórios espaciais variantes mensalmente).

A Tabela 6.8 permite algumas conclusões importante em termos de ajuste. O primeiro está na importância dos componentes latentes (efeitos dinâmicos e espaciais) no ajuste do modelo. Há um ganho bastante relevante em relação aos modelos com estes componentes em comparação aos modelos lineares simples, como podem ser observados em todas as métricas. A segunda conclusão é que as restrições no conjunto de covariadas não retiram poder significante de ajuste no modelo, já que não existe piora relevante com a restrição destas imposições em termos de RMSE, MAE, MPE e MAPE. Outro resultado importante está no ganho obtido com o uso de efeitos espaciais variantes no tempo, que permitem uma redução adicional nos critérios de erro de ajuste. Também podemos observar que a parametrização com efeitos aleatórios espaciais anuais obtém o melhor ajuste entre todas as especificações analisadas, indicando que esta parametrização obtém um bom ajuste mesmo com restrição que os efeitos espaciais sejam constantes em cada ano. 


\section{Conclusão}

Este trabalho apresenta uma nova forma de modelar a razão preço por metro quadrado dos lançamentos imobiliários, utilizando-se um modelo espaço-temporal com efeitos aleatórios projetados continuamente no espaço. Além do componente estocástico, este modelo introduziu uma nova metodologia que permite incorporar componentes determinísticos de tendência e ciclo aos modelos hedônicos de preços.

A análise dos atributos hedônicos e dos respectivos impactos dos componentes sistêmicos (tendência e ciclo) do modelo podem permitir, aos atuantes no mercado imobiliário, uma melhor percepção das dinâmicas e a forma por meio do qual os imóveis são lançados e comercializados em cada localidade. Esta análise do modelo pode apresentar implicações financeiras, estratégicas e até políticas, a depender do objetivo do usuário.

Dentre as implicações financeiras, podemos citar o caso em que o agente esteja em busca de auferir ganhos financeiros com a comercialização do imóvel, ou até mitigar uma perda futura. Uma vez que os valores e benefícios de um determinado imóvel dependam do conjunto de atributos intrínsecos e extrínsecos. Deve-se, nos estágios de sondagem, proposta e planejamento, considerar os atributos de cada localização, de acordo com as preferências de cada agente.

Este trabalho também mostra a importância de se controlar para os aspectos dinâmicos e espaciais na modelagem de preços de imóveis, indicando que as covariadas podem ser insuficientes para capturar todos os fatores relevantes no apreçamento dos novos lançamentos imobiliários. Os componentes de tendência e ciclo são importantes para capturar os aspectos de mudança no padrão sistemático dos preços, capturando os elementos de mudança não-estacionária através da tendência, e componentes periódicos, como possíveis períodos de valorização e queda nos preços. O trabalho também evidencia a natureza fundamental dos aspectos espaciais na análise de ativos imobiliários, um aspecto muitas vezes negligenciado em modelos hedônicos.

O trabalho também contribui com diversos aspectos metodológicos em relação aos métodos econométricos usuais utilizados na análise de ativos imobiliários. O método permite tratar o processo de preços como evoluindo continuamente no espaço, evitando o uso das agregações espaciais necessárias aos modelos tradicionais de econometria espacial, baseados em estruturas irreais (lattices). As agregações eliminam os aspectos individuais de cada lançamento, o que pode representar um tratamento ineficiente da rica informação disponível nesta classe de base de dados. Outro aspecto importante em relação aos modelos usuais de econometria espacial é a introdução de estruturas dinâmicas na modelagem, tanto com a introdução dos chamados componentes sistemáticos estruturais em uma decomposição de tendência e ciclo comuns, como também a possibilidade de tornar os efeitos aleatórios espaciais variantes no tempo, capturando as mudanças no padrão de 
dispersão espacial de preços.

Como possíveis extensões deste estudo, pode-se considerar a incorporação de novas variáveis independentes com características intrínsecas ou extrínsecas, bem como, o próprio método pode ser estendido a outras regiões de interesse. Podendo ainda, ser estendido para outras disciplinas em que se possa adaptar outro tipo de modelo hedônico em que se possam incorporar os componentes sistêmicos (tendência, ciclo e componentes espaciais).

\section{Referências}

ABRAMOWITZ, M.; STEGUN, I. A. Handbook of mathematical functions: with formulas, graphs, and mathematical tables. [S.l.]: Courier Corporation, 1964. v. 55.

ALVES, D. C. de O. et al. Modelagem dos preços de imóveis residenciais paulistanos. Revista Brasileira de Finanças, Sociedade Brasileira de Finanças, v. 9, n. 2, p. 167-187, 2011.

ARBIA, G. Spatial econometrics: statistical foundations and applications to regional convergence. [S.1.]: Springer Science \& Business Media, 2006.

BAILY, M. N.; LITAN, R. E.; JOHNSON, M. S. The origins of the financial crisis. [S.l.]: Initiative on Business and Public Policy at Brookings, 2008.

BAKKA, H. et al. Spatial modelling with R-INLA: A review. [S.l.], 2018.

BERG, M. D. et al. Computational Geometry: Introduction. [S.l.]: Springer, 2008.

BESAG, J.; MONDAL, D. First-order intrinsic autoregressions and the de wijs process. Biometrika, Oxford University Press, v. 92, n. 4, p. 909-920, 2005.

BLANGIARDO, M.; CAMELETTI, M. Spatial and Spatio-Temporal Models with R-INLA. [S.l.]: Wiley, 2015.

BOLIN, D. Models and methods for random fields in spatial statistics with computational efficiency from Markov properties. [S.l.]: Lund University, 2012. v. 2012.

BOWEN, W. M. Theoretical and empirical considerations regarding space in hedonic housing price model applications. Growth and Change, Wiley Blackwell, v. 32, n. 4, p. 466-490, 2001.

BRENNER, S.; SCOTT, R. The mathematical theory of finite element methods. [S.1.]: Springer Science \& Business Media, 2007. v. 15.

CAMELETTI, M. et al. Spatio-temporal modeling of particulate matter concentration through the spde approach. AStA Advances in Statistical Analysis, Springer, v. 97, n. 2, p. 109-131, 2013.

CLARK, D. E. Externality effects on residential property values: The example of noise disamenities. Growth and Change, Wiley Online Library, v. 37, n. 3, p. 460-488, 2006. 
CLARK, J. S.; GELFAND, A. E. Hierarchical modelling for the environmental sciences: statistical methods and applications. [S.1.]: Oxford University Press on Demand, 2006.

FARIA, R. C. d. et al. Uma aplicação do método de preços hedônicos no setor saneamento: O projeto de são bento do sul-sc. Planejamento e Políticas Públicas, v. 1, n. 31, 2009.

FREEMAN, A. M. Hedonic prices, property values and measuring environmental benefits: a survey of the issues. In: Measurement in Public Choice. [S.l.]: Springer, 1981. p. 13-32.

GELMAN, A.; HWANG, J.; VEHTARI, A. Understanding predictive information criteria for bayesian models. Statistics and Computing, Springer, v. 24, n. 6, p. 997-1016, 2014.

HARVEY, A. C. Forecasting, structural time series models and the Kalman filter. [S.1.]: Cambridge university press, 1990.

HOLLY, S.; PESARAN, M. H.; YAMAGATA, T. A spatio-temporal model of house prices in the usa. Journal of Econometrics, Elsevier, v. 158, n. 1, p. 160-173, 2010.

LAURINI, M. P. A continuous spatio-temporal model for house prices in the usa. The Annals of Regional Science, Springer, p. 1-35, 2016.

LAURINI, M. P. Income estimation using night luminosity: A continuous spatial model. Spatial Demography, Springer, v. 4, n. 2, p. 83-115, 2016.

LINDGREN, F.; RUE, H.; LINDSTRÖM, J. An explicit link between gaussian fields and gaussian markov random fields: the stochastic partial differential equation approach. Journal of the Royal Statistical Society: Series B (Statistical Methodology), Wiley Online Library, v. 73, n. 4, p. 423-498, 2011.

PAUlinO, C. D. M.; TURKMAN, M. A. A.; MURTEIRA, B. Estatística bayesiana. [S.l.: s.n.], 2003.

ROZANOV, J. A. Markov random fields and stochastic partial differential equations. Sbornik: Mathematics, Turpion Ltd, v. 32, n. 4, p. 515-534, 1977.

RUE, H.; HELD, L. Gaussian Markov random fields: theory and applications. [S.l.]: CRC Press, 2005.

RUE, H.; MARTINO, S.; CHOPIN, N. Approximate bayesian inference for latent gaussian models by using integrated nested Laplace approximations. Journal of the royal statistical society: Series b (statistical methodology), Wiley Online Library, v. 71, n. 2, p. 319-392, 2009 .

RUE, H. et al. Bayesian computing with inla: A review. Annual Review of Statistics and Its Application, v. 4, n. 4, p. 395-421, 2017.

SCHILLER, R. J. Irrational exuberance. Princeton UP, Wiley Online Library, 2000.

SPIEGLHALTER, D. et al. Bayesian measures of model complexity and fit (with discussion). Journal of the Royal Statistical, Series B, v. 64, p. 583-616, 2002.

TEIXEIRA, E. C.; SERRA, M. A. O impacto da criminalidade no valor da locação de imóveis: o caso de curitiba. Economia e Sociedade, v. 15, n. 1, p. 175-207, 2016. 
TITA, G. E.; PETRAS, T. L.; GREENBAUM, R. T. Crime and residential choice: a neighborhood level analysis of the impact of crime on housing prices. Journal of Quantitative Criminology, Springer, v. 22, n. 4, p. 299-317, 2006.

WATANABE, S. Asymptotic equivalence of bayes cross validation and widely applicable information criterion in singular learning theory. Journal of Machine Learning Research, v. 11, n. Dec, p. 3571-3594, 2010.

WHITTLE, P. On stationary processes in the plane. Biometrika, JSTOR, p. 434-449, 1954. 


\section{Anexo}

Figura 8.1 - Mapa geográfico com a cidade de São Paulo.

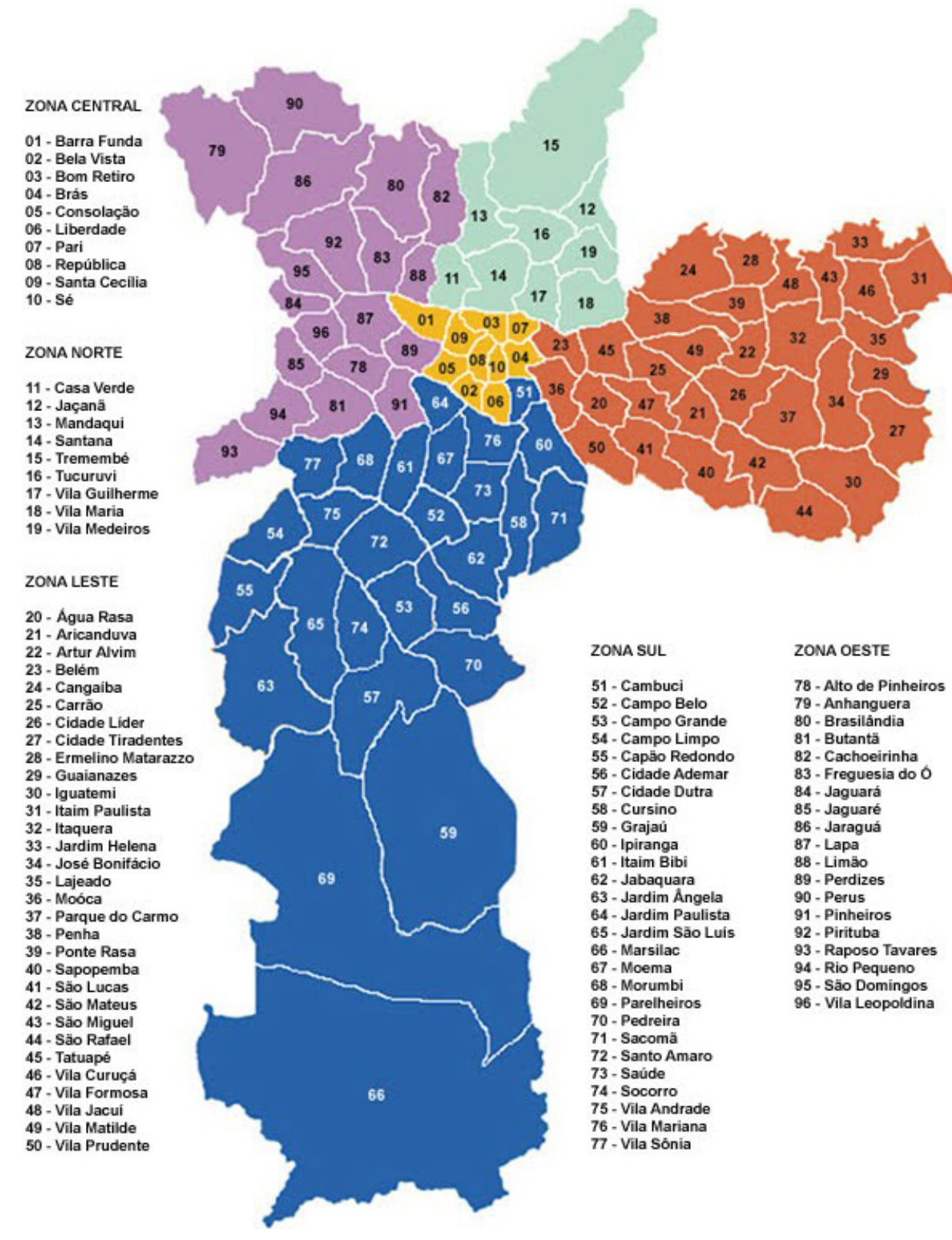

